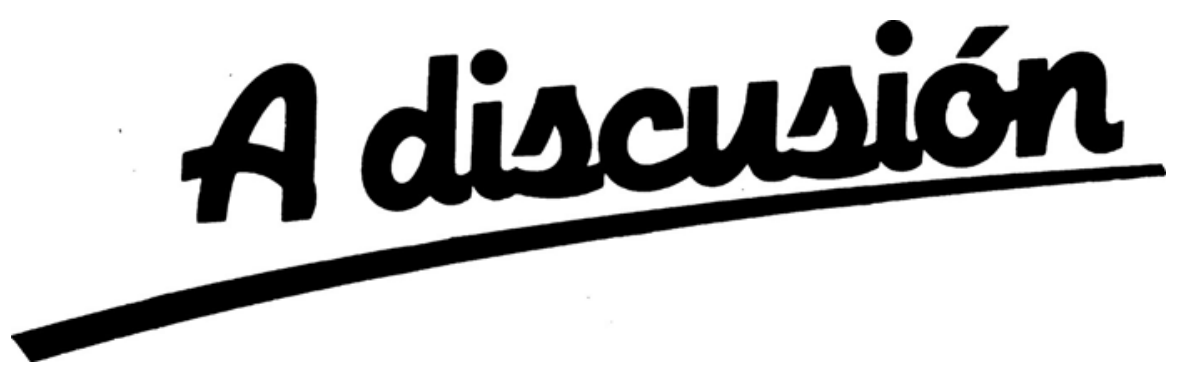

\title{
ASSET PRICING IN A GENERAL EQUILIBRIUM PRODUCTION ECONOMY WITH CHEW-DEKEL RISK PREFERENCES*
}

\section{Claudio Campanale, Rui Castro and Gian Luca Clementi**}

WP-AD 2008-14

Corresponding author: C. Campanale. Dpt. Fundamentos del Análisis Económico, Universidad de Alicante. Campus de S. Vicente del Raspeig, 03690, Alicante, Spain. E-mail: claudio@merlin.fae.ua.es.

Editor: Instituto Valenciano de Investigaciones Económicas, S.A.

Primera Edición Octubre 2008

Depósito Legal: V-4541-2008

IVIE working papers offer in advance the results of economic research under way in order to encourage a discussion process before sending them to scientific journals for their final publication.

\footnotetext{
* We thank Dave Backus, Alberto Bisin, Michele Boldrin, Satyajit Chatterjee, Hal Cole, Tom Cosimano, Max Croce, Jean-Sébastien Fontaine, René Garcia, Sydney Ludvigson, Dino Palazzo, B. Ravikumar, Bryan Routledge, Stan Zin, as well seminar attendants at NYU, Notre Dame, Philadelphia Fed, Purdue, Texas A\&M, and Wisconsin for their comments and suggestions. All remaining errors are our own responsibility. Clementi thanks CIREQ and the Department of Economics at the Université de Montréal for their generous hospitality at various stages of this project.

** C. Campanale: Department of Economics, Universidad de Alicante. R. Castro: Department of Economics and CIREQ, Université de Montréal. G.L. Clementi: Department of Economics, Stern School of Business, New York University.
} 


\title{
Asset Pricing in a General Equilibrium Production Economy with Chew-Dekel Risk Preferences
}

\author{
Claudio Campanale Rui Castro Gian Luca Clementi
}

\begin{abstract}
In this paper we provide a thorough characterization of the asset returns implied by a simple general equilibrium production economy with convex investment adjustment costs. When households have Epstein-Zin preferences, there exist plausible parameter values such that the model generates unconditional mean risk-free rate and equity return, and volatility of consumption growth, which are in line with historical averages for the US economy. Consistently with the data, the model's implied price-dividend ratio is pro-cyclical and stock returns are predictable (and increasingly so as the time horizon increases), while dividend growth is not. The model also implies realistic values for (i) the correlation of the risk-free rate with output growth and consumption growth and (ii) the correlation pattern between risk-free rate, equity return, and equity premium. The risk implied by the model is rather low. At the modal state of nature, an individual that expects to consume for 100,000 dollars a year faces a lottery over future consumption with a standard deviation of 55 dollars (per quarter). Her risk aversion is such that she's willing to pay 1 dollar (per quarter) in order to avoid that lottery. Very similar results can be obtained assuming that agents are disappointment averse in the sense of Gul (1991). With such risk preferences, the universality requirement is not a problem to the extent that it is in the case of expected utility. In fact, faced with a lottery that has a coefficient of variation 100 times as large as that implied by our model, a disappointment averse agent displays the same relative risk aversion as an expected utility agent with logarithmic utility!
\end{abstract}

Key words. Equity Premium, Business Cycle, Predictability, Disappointment Aversion.

JEL Codes: D81, E32, E43, E44, G12. 


\section{Introduction}

In this paper we provide a thorough characterization of the asset returns implied by a simple variant of the neoclassical growth model, the workhorse of business cycle analysis since the seminal work of Kydland and Prescott (1982). First, we show the existence of reasonable parameter values such that the model matches the unconditional first moments of risk-free rate and equity premium, while generating volatility of output growth and consumption growth consistent with the empirical evidence. Then, we go on to study the dynamics of asset returns. We show that, again consistently with quarterly data for the US economy, (i) the price-dividend ratio is strongly pro-cyclical, (ii) the risk-free rate is essentially uncorrelated with output growth, and (iii) risk-free rate and equity return are moderately positively correlated. Furthermore, stock returns are forecastable using price-dividend ratios and the predictive power of the latter increases with the time horizon. Dividend growth, on the other hand, is not forecastable. These facts are consistent with what first found by Campbell and Shiller (1988) and Fama and French (1988a). The main shortcomings of the model appear to be (i) the excessive volatility of the risk-free rate and (ii) the lack of predictability of the equity premium.

Since the provocative paper by Mehra and Prescott (1985), scholars working on general equilibrium models of asset returns have made giant steps forward. However, most of this progress is the result of the analysis of endowment economies, along the lines of Lucas (1978). During the same period, following the lead of Kydland and Prescott (1982), business cycle analysis has also made great advances. For example, it was shown that the neoclassical stochastic growth model, when parameterized to match stylized low-frequency facts about the US economy, generates a joint highfrequency dynamics of aggregate output, consumption, and investment which is also consistent with NIPA data (see Cooley and Prescott (1995)). Here, by neoclassical stochastic growth model we mean a general equilibrium dynamic economy with capital accumulation, where households maximize expected discounted utility, markets are complete, and multiplicative shocks to the production function are the only stochastic disturbance.

The asset pricing implications generated by the stochastic growth model should be of interest to both finance and business cycle scholars. On the one hand, its implications for macroeconomic quantities arise from the equality of marginal rates of substitution to marginal rates of transformation. These, in turn, directly identify 
securities returns. Squaring the latter against the data provides a further opportunity for model's falsification. On the other hand, as argued by Cochrane (2006) among others, endowment economies are not that useful when the objective is to understand what macroeconomic factors lie behind the factor portfolios that have been shown to have predictive power for asset returns. Yet, the literature on the asset pricing implications of general production economies such as the stochastic growth model is still in its infancy.

To our knowledge, the first comprehensive analysis of the asset pricing implications of the stochastic growth model is due to Rouwenhorst (1995). His main result is that, for such model, matching the unconditional mean equity premium is even harder than for Mehra and Prescott (1985)'s economy. This is the case for two main reasons. First, differently from what happens in an endowment economy, raising the coefficient of relative risk-aversion does not help to increase the volatility of the stochastic discount factor. In fact, higher risk aversion implies lower elasticity of substitution, and therefore lower volatility of consumption growth. Second, the price of capital being constant at 1 , the volatility of stock returns is equal to that of the marginal product of capital, which is quite limited in this framework.

Tallarini (2000) shows that the first of the two issues outlined above can be addressed by allowing for the decoupling of risk aversion and elasticity of intertemporal substitution. By assuming Epstein-Zin preferences, he is able to raise risk aversion at arbitrarily high levels, while keeping the elasticity of substitution anchored at 1. Tallarini (2000) shows that there exist values of the RRA coefficient such that the stochastic growth model generates a market price of risk consistent with the empirical evidence. However, the price of capital being constant at 1 , his model cannot generate sizeable equity premia.

Jermann (1998) and Boldrin, Christiano, and Fisher (2001) deal with both of the issues raised by Rouwenhorst (1995), by assuming that agents form consumption habits and that the allocation of capital cannot adjust immediately or costlessly to productivity shocks. In Jermann (1998), the latter feature is obtained by means of convex adjustment costs, while Boldrin, Christiano, and Fisher (2001) assume the existence of two production sectors, with limited inter-sectoral factor mobility. These impediments to the smooth adjustment of capital imply that the price of capital is not anchored to 1 any longer. However, without limiting households' willingness to substitute consumption intertemporally, this will not have much of an impact on the volatility of capital gains and therefore on the volatility of stock returns. The 
main effects will be to lower the volatility of investment and to increase that of consumption growth (via the economy's resource constraint). The low elasticity of intertemporal substitution implied by habit preferences deals with this issue, leading to higher volatility of stock returns without counterfactual implications for the second moments of investment and consumption growth. The increase in the curvature of the utility function, by increasing risk-aversion, takes care of increasing the volatility of the stochastic discount factor.

Here we show that similar results can be obtained under the assumption that households' risk preferences over atemporal lotteries fall in the Chew-Dekel class. We consider two of such preference relations. One is the well known structure leading to the expected utility representation. The other, due to Gul (1991), allows for disappointment aversion. Following Kreps and Porteus (1978) and Epstein and Zin (1989), we imbed these preference relations in a standard intertemporal choice problem, to obtain two utility criteria for evaluating stochastic sequences, known in the literature as Epstein-Zin and disappointment aversion, respectively.

We assign values to parameters, following the methodology typical of most modern macroeconomic studies. Whenever possible, we use direct empirical evidence. Alternatively, we choose them so that the model is consistent with certain low-frequency statistics for the US economy. This procedure leaves us with three parameters, governing relative risk-aversion, the elasticity of intertemporal substitution, and the elasticity of investment to Tobin's $q$, respectively. We pick their values so that our model matches the unconditional mean risk-free rate and equity premium, and the ratio of volatility of consumption growth to volatility of output growth. When households have Epstein-Zin preferences, the resulting coefficient of relative risk aversion with respect to atemporal bets is about 18, the elasticity of intertemporal substitution is about $1 / 39$, and the average elasticity of investment to Tobin's $q$ is 0.77 . Such a low value for the elasticity of substitution falls within the confidence interval for this parameter, as estimated by several empirical studies (see Hall (1988), for example). Unfortunately, the parsimony of our model does not allow to directly compare the model's implied average elasticity of investment with respect to $q$ to estimates obtained by the empirical literature on investment. However, the evidence discussed in Section 4 suggests that our value is by no means unreasonable. Admittedly, the RRA coefficient is larger than most economists have so far been comfortable with. In Section 4, we argue that the RRA coefficient is not the ideal measure of risk aversion in this environment. We find it more compelling to consider the level of relative risk 
aversion implied by the model along the equilibrium path. That is, the relative risk aversion evaluated at the risk implied by the model. Such value turns out to be quite reasonable. As expected, the same specification of risk preferences, when used to evaluate atemporal lotteries involving much greater risk than that generated by our model, implies dramatically higher relative risk aversion. In Section 5, we document that this issue does not arise when agents are disappointment averse. To this end, the relevant property of this preference relation is first-order risk aversion. As far as we know, this insight is due to Epstein and Zin (1990a), who consider rank-dependent preferences in a Mehra-Prescott economy. ${ }^{1}$ Here we show that it also works in the case of a production economy. That is, we show that 1) there exists a value for the disappointment aversion parameter, such that the model has essentially the same implications for both quantities and prices as the model with Epstein-Zin preferences and that 2) when the disappointment averse agent is faced with an atemporal lottery that has a coefficient of variation 100 times as large as that implied by our model, she displays the same relative risk aversion as an expected utility agent with logarithmic utility.

The main shortcomings of the model are the excessive volatility of the risk-free rate and the lack of predictability of the equity premium. For the expected equity premium to be time-varying, the volatility of stock returns or the price of risk, or both, must also be time-varying. Since the stochastic process for the only shock in the model is homoscedastic and risk aversion is acylical, the occurrence of the latter problem is not surprising. We show that Routledge and Zin (2004)'s generalization of disappointment aversion, by generating a time-varying price of risk, has the potential to address the second of the two shortcomings. This result mirrors that obtained by Routledge and Zin (2004) in the case of a Mehra-Prescott economy. However, the counterfactually high volatility of the risk free rate undermines the model's ability to generate predictability to the extent implied by the data.

A corollary of our results is that, when considering the asset pricing implications of general equilibrium, complete-market production economies, there is no apparent reason why one should abandon Chew-Dekel preferences in favor of habit-based preference specifications. In fact, comparing our results with those of Jermann (1998) and Boldrin, Christiano, and Fisher (2001), it emerges that introducing habit does not improve the ability of the model to generate sensible asset pricing implications. Work-

\footnotetext{
${ }^{1}$ Epstein and Zin (2001) and Bonomo and Garcia (1994) exploited it when considering disappointment aversion, still in the context of an endowment economy.
} 
ing with Chew-Dekel preferences is more appealing to us, for a number or reasons. To start with, the largest part the business cycle literature does not rely on habit formation. Secondly, Chew-Dekel preferences clearly allow for aggregation, in complete market economies. This implies that asset prices do not depend on the distribution of wealth. We are not aware of any proof that this is the case when some form of habit is assumed. ${ }^{2}$ A further shortcoming of habit models is that the dependence of utility on the reference point (i.e. the habit) and the evolution of that reference point over time and across states, depends on the particular application under consideration. Referring to models with habit formation, Pesendorfer (2006) argues that "This research seeks the right utility function for a particular application". This criticism does not apply to axiomatic-based preference relations such as those postulated in this paper. Once again in the words of Pesendorfer (2006), "Standard economic models relate behavior in different situations. For example, the Epstein-Zin axioms describe how the decision-maker behaves in simple situations and the formula derived in the representation theorem (applied to an economic decision problem) describes how decisions are made in more complicated economic problems."

Finally, we notice that our work is also quite close to other recent analyses of asset returns in general equilibrium production economies. Danthine and Donaldson (2002) and Guvenen (2005) focus on household heterogeneity, constructing environments in which stock market participants' consumption growth is more volatile because these agents provide insurance against aggregate shocks to non-participants. ${ }^{3}$ Papanikolaou (2006) studies the asset pricing implications of investment-specific technological change. Finally, Croce (2006)'s evaluates the welfare costs of business cycles implied by an economy with Epstein-Zin preferences and long-run risk à la Bansal and Yaron (2004), parameterized to match some moments of asset returns.

The remainder of the paper is organized as follows. The model is introduced in Section 2. Section 3 characterizes the properties of asset returns in the case of EpsteinZin preferences. Section 4 assesses the parameter values implied by our calibration procedure. The asset prices implications of disappointment aversion are characterized in Section 5. The concluding remarks are in Section 6.

\footnotetext{
${ }^{2}$ Our hunch is that an aggregation result may be proved with external habit, but not in the case of internal.

${ }^{3}$ In Danthine and Donaldson (2002), the fraction of agents excluded from the stock market coincide with workers. While being denied the possibility of using capital accumulation for consumption smoothing, these agents obtain insurance from the firms' owners by means of labor contracts. In Guvenen (2005), non-participants are assumed to have a lower elasticity of intertemporal substitution. This stronger consumption smoothing motive can be satisfied only by trading in bonds with the owners of capital. In turn, this implies a more volatile consumption growth for the latter.
} 


\section{The Model}

Ours is a simple version of the standard neoclassical growth model. Time is discrete and runs from $t=0$ to infinity. The economy consists of a large number of identical and infinitely lived households that derive utility uniquely from consumption. Production takes place in firms, that finance the purchase of capital by selling claims to their cash flows to households. Two are the differences from the standard framework used for business cycle analysis: labor supply is inelastic (it is assumed that each agent provides one unit of labor every period) and adjusting the capital stock is costly.

We denote by $S_{t}=\left\{s_{v}\right\}_{v=0}^{t}$ the history of the economy between dates 0 and $t$. In other words, $S_{t}$ contains all payoff-relevant information as of time $t$. Once specified the other assumptions, we will be able to define its elements.

\section{$2.1 \quad$ Preferences}

We follow Kreps and Porteus (1978) and Epstein and Zin (1989) in constructing preference orderings over stochastic sequences of consumption by adopting a Koopman's time aggregator and risk-preferences in the Chew-Dekel class. ${ }^{4}$

In particular, we assume that after every history $S_{t}$, agents value stochastic sequences of consumption $\left\{c_{v}\right\}_{v=t}^{\infty}$ by means of the time aggregator

$$
v\left(S_{t}\right) \equiv\left[c_{t}^{\gamma}+\beta \mu^{\gamma}\left(S_{t}\right)\right]^{1 / \gamma}, \quad \gamma \leq 1, \beta>0,
$$

where $\mu\left(S_{t}\right)$ represents the certainty equivalent of the lottery over the streams of utility associated to all histories $S_{t} \cup\left\{s_{v}\right\}_{v=t+1}^{\infty}$, and $\beta$ defines the relative importance of future versus current utility. Obviously, the nature of the certainty equivalent $\mu(\cdot)$ will depend on the preference relation over atemporal lotteries that is assumed. In this paper we will consider two popular formulations, known in the literature as expected utility and disappointment aversion. ${ }^{5}$

\footnotetext{
${ }^{4}$ By time-aggregator we simply mean a criterion for evaluating deterministic sequences of consumption. Koopmans (1960) characterizes the set of aggregators that satisfy the conditions of history independence, future independence, and stationarity. Chew (1989) and Dekel (1986) derive a class of risk preferences that include expected utility as a special case and lead to first-order conditions that are linear in probabilities. See Backus, Routledge, and Zin (2004) for a careful yet readable summary of this literature.

${ }^{5} \mathrm{As}$ is well known, expected utility is the representation of a preference relation satisfying the axioms of monotonicity, completeness, transitivity, continuity, and independence. Disappointment Aversion and its generalization due to Routledge and Zin (2004) relax the latter, replacing it with weaker requirements, known as the Gul's weak independence axiom and the $\delta$-weak independence axiom, respectively. See Routledge and Zin (2004) for a careful yet readable exposition of these issues.
} 
It turns out that the utility representations admitted by both relations can be expressed as special cases of the representation of generalized disappointment aversion, due to Routledge and Zin (2004). Under the generalized disappointment aversion criterion, an agent evaluating a lottery attaches a penalty in utility terms to events that she considers disappointing. These are all the events that fall below her disappointment threshold, given by the certainty equivalent scaled by the parameter $\xi>0$. Therefore, the certainty equivalent $\mu\left(S_{t}\right)$ satisfies the following condition:

$$
\begin{aligned}
\mu^{\eta}\left(S_{t}\right) & =\sum_{S_{t+1}} \pi\left(S_{t+1} \mid S_{t}\right) v^{\eta}\left(S_{t+1}\right)-\theta \sum_{S_{t+1} \in \Delta_{t+1}} \pi\left(S_{t+1} \mid S_{t}\right)\left\{\left[\xi \mu\left(S_{t}\right)\right]^{\eta}-v^{\eta}\left(S_{t+1}\right)\right\} \\
\Delta_{t+1} & =\left\{S_{t+1}: v\left(S_{t+1}\right)<\xi \mu\left(S_{t}\right)\right\}, \quad \eta \leq 1, \theta \geq 0, \xi \geq 0 .
\end{aligned}
$$

With $\pi\left(S_{t+1} \mid S_{t}\right)$ we denote the probability of history $S_{t+1}$, conditional on $S_{t}$ having occurred. The set $\Delta_{t+1}$ is the set of disappointing payoffs. Disappointment aversion is obtained by setting $\xi=1$. Expected utility obtains for $\theta=0$.

\subsection{Production and Capital Accumulation}

We assume that population grows at the constant rate $\varphi \geq 0$. For simplicity, we are going to express all variables in per-capita terms. Aggregate output $y_{t}$ is produced according to

$$
y_{t}=k_{t}^{\alpha}\left(z_{t} l_{t}\right)^{1-\alpha},
$$

where $k_{t}$ and $l_{t}$ are the capital and labor inputs, respectively, and $0<\alpha<1$. Labor augmenting technological progress at time $t$ is given by

$$
z_{t}=e^{\lambda t+\varepsilon_{t}}
$$

where $\lambda>0$ and $\varepsilon_{t}=\rho \varepsilon_{t-1}+\zeta_{t}, \quad \zeta_{t} \sim N\left(0, \sigma^{2}\right)$. As commonly assumed in theoretical studies of the business cycle, deviations from the linear time-trend follow a first-order autoregressive process. This formulation implies that productivity growth follows a stationary $M A(\infty)$ process:

$$
\log \left(z_{t+1} / z_{t}\right)=\lambda+(\rho-1) \sum_{s=0}^{\infty} \rho^{s} \zeta_{t-s}+\zeta_{t+1} .
$$

Investment at time $t$ is subject to adjustment costs according to the function $g\left(k_{t}, k_{t+1}\right)$, where $g(\cdot, \cdot)$ is twice differentiable, strictly increasing and strictly convex in $k_{t+1}$, and linearly homogenous in $k_{t}$. In the analysis that follows, we will assume that

$$
g\left(k_{t}, k_{t+1}\right) \equiv\left|\frac{k_{t+1}}{k_{t}}-\psi\right|^{\iota} k_{t}, \quad \iota>1, \psi>0 .
$$


Finally, letting $i$ denote gross investment, the per-capita capital stock evolves according to

$$
k_{t+1}=i_{t}+(1-\delta) k_{t}
$$

and the aggregate resource constraint is

$$
y_{t}=c_{t}+i_{t}+g\left(k_{t}, k_{t+1}\right)
$$

The timing and the resolution of uncertainty are as usual. It follows that the history $S_{t}$ can be summarized by the pair $\left(k_{t}, z_{t}\right)$.

\subsection{The Planner's Problem}

Following much of the literature, we characterize the equilibrium allocation by solving the planner's problem. Expressed in terms of trend-stationary variables, the latter can be written in recursive form as

$$
v(k, \varepsilon)=\max _{k^{\prime}}\left\{c^{\gamma}+\beta e^{[\varphi+\gamma \lambda]} \mu\left[v\left(k^{\prime}, \varepsilon^{\prime}\right)\right]^{\gamma}\right\}^{1 / \gamma}
$$

subject to

$$
\begin{aligned}
c+e^{(\lambda+\varphi)} k^{\prime} & =k^{\alpha}\left(e^{\varepsilon} l\right)^{1-\alpha}+(1-\delta) k-\left|e^{(\lambda+\varphi)} \frac{k^{\prime}}{k}-\psi\right|^{\iota} k \\
\varepsilon^{\prime} & =\rho \varepsilon+\zeta^{\prime}, \quad \zeta^{\prime} \sim N\left(0, \sigma^{2}\right),
\end{aligned}
$$

where $\mu \equiv \mu\left[v\left(k^{\prime}, \varepsilon^{\prime}\right)\right]$ solves

$$
\mu^{\eta}=\mathrm{E}_{\varepsilon^{\prime}}\left\{\frac{\left[1+\theta I\left(k^{\prime}, \varepsilon^{\prime}, \mu\right)\right] v^{\eta}\left(\varepsilon^{\prime}, z^{\prime}\right)}{1+\theta \mathrm{E}_{\varepsilon^{\prime}}\left[I\left(k^{\prime}, \varepsilon^{\prime}, \mu\right)\right]}\right\}, I\left(k^{\prime}, \varepsilon^{\prime}, \mu\right)= \begin{cases}1 & \text { if } v\left(k^{\prime}, \varepsilon^{\prime}\right)<\xi \mu, \\ 0 & \text { otherwise. }\end{cases}
$$

This framework nests some of the most popular models in the asset pricing literature. By setting $\xi=1$, one obtains the case of Disappointment Aversion. Further, by posing $\theta=0$, one recovers what is known as the Epstein-Zin model. Finally, for $\gamma=\eta$, we obtain the classical case of expected discounted utility. Throughout this paper, we will assume $\psi=e^{\lambda+\varphi}$. That is, we will assume that adjustment costs are strictly positive if and only if capital grows at a rate different from its balanced growth level. Under this assumption, as pointed out by Abel (2002), the balanced growth rate of the economy will be invariant to the parameter $\iota$.

\subsection{Asset Returns}

As in most of the asset pricing literature, our analysis will focus on two assets, which we call risk-free asset and equity, respectively. In the data, we will identify the former 
with the 3-month Treasury Bill and the latter with a portfolio of stocks traded on the New York Stock Exchange. Details on data sources and elaboration are confined to Appendix A. The theoretical counterpart of the 3-month T-Bill will be a 1-period lived asset that delivers one unit of consumption in all states of nature. Its conditional gross return, denoted as $R^{f}(k, z)$, satisfies ${ }^{6}$

$$
\sum_{i} \pi\left(\varepsilon_{i} \mid \varepsilon\right) m\left(\varepsilon_{i} \mid k, \varepsilon\right) R^{f}(k, \varepsilon)=1
$$

The term $m\left(\varepsilon_{i} \mid k, \varepsilon\right)$ is known in the literature as the stochastic discount factor. Its specification depends on the assumption on risk-preferences.

Following Cochrane (1991), Jermann (1998) and Boldrin, Christiano, and Fisher (2001), we identify the gross return on equity (conditional on state $i$ ) with the marginal gross return on investment. That is, we posit that

$$
R^{e}\left(k, \varepsilon ; \varepsilon_{i}\right)=\frac{\alpha k^{\prime \alpha-1}\left(\varepsilon_{i} l^{\prime}\right)^{1-\alpha}+(1-\delta)-\frac{\partial}{\partial k^{\prime}} g\left[k^{\prime}, k^{\prime \prime}\left(k^{\prime}, \varepsilon_{i}\right)\right]}{1+e^{-(\lambda+\varphi)} \frac{\partial}{\partial k^{\prime}} g\left(k, k^{\prime}\right)} .
$$

The expected conditional return is then computed as

$$
E\left[R^{e}(k, \varepsilon)\right]=\sum_{i} \pi\left(\varepsilon_{i} \mid \varepsilon\right) R^{e}\left(k, \varepsilon ; \varepsilon_{i}\right)
$$

In Appendix B, we show that expression (2) is implied by a decentralization of the planner's problem where production is carried out by firms that maximize the sum of expected discounted dividends and finance investment by means of retained earnings only.

There are reasons why defining (2) as the theoretical counterpart to the return on a stock portfolio is short of ideal. To start with, as shown in Appendix B, it identifies aggregate dividends as the difference between aggregate consumption and the labor share of aggregate income, which also equals the net resource flow from the corporate sector to the household sector. When consumption is greater than the labor share of income, the net payout of the corporate sector is positive. This is the case in which the capital share of output is greater than gross investment. However, when consumption is lower than the labor share of income, the net payout of the corporate sector is negative. This is because the capital share of income is not sufficient to finance gross investment. Households invest part of their labor income in the corporate sector. Therefore, $R^{e}\left(k, \varepsilon ; \varepsilon_{i}\right)$ is the return to shareholders, once eventual new investments

\footnotetext{
${ }^{6}$ In the remainder of the paper, our notation will reflect the fact that our numerical procedure involves approximating the stochastic process for the productivity shock $\varepsilon$ by means of a 6 -state Markov chain.
} 
are taken into account. This implies that a more appropriate empirical counterpart of the payout to shareholders in this model consists of the gross flow of resources from the corporate sector to the household sector (dividends, shares and bonds repurchase, interest payments on bonds, interest payments on other loans, extinguishment of loans) minus the gross flow of resources from the household sector to the corporate sector (gross issue of equity and bonds plus new loans). A related issue is that in our decentralization firms are assumed to be completely equity-financed. This is obviously not the case for those corporations whose stocks form the market portfolios used in all asset pricing studies. ${ }^{7}$

\subsection{Numerical Approximation and Simulation}

As it should be clear by now, we are interested in comparing our model's implications for a set of moments of prices and quantities, with their empirical counterparts. The moments' point estimates reported in the remainder of the paper are the output of an algorithm that involves i) obtaining a numerical approximations to the optimal policy for consumption generated by the optimization program (1) and ii) applying standard Montercarlo simulation methods in order to approximate the stationary distribution of capital implied by that policy.

In the business cycle literature, the policy functions implied by models as simple as ours are often computed by means of low-order perturbation methods. Most commonly, by means of a log-linear approximation. For standard preference specification and parameter values, the validity of this approach has been established by several authors. For example, Aruoba, Fernandez-Villaverde, and Rubio-Ramirez (2006) carry out a very detailed comparison of several approximation algorithms, to conclude that perturbation methods are fairly accurate when risk aversion and the variance of the shock are small. When these conditions are not met, finite element methods and Chebyshev polynomials always perform better. Unfortunately for us, Aruoba, Fernandez-Villaverde, and Rubio-Ramirez (2006) restrict their tests to quantities, i.e. they do not compare the asset pricing implications obtained by applying different methods. Recently, John Cochrane expressed some skepticism about the accuracy of asset pricing moments' approximations obtained by low-order perturbation.

\footnotetext{
${ }^{7}$ These observations also constitute the premise of a recent paper by Gomme, Ravikumar, and Rupert (2006). Their approach, however, is rather different. In their work, the empirical counterpart of the return on equity generated by the model is not the return on an equity portfolio, but rather the return to a measure of aggregate business capital, which they construct using data from the National Income and Product Accounts.
} 
In Cochrane (2006), he writes: "I remain a bit worried about the accuracy of approximations in general equilibrium model solutions. Most papers solve their models by making a linear-quadratic approximation about a non-stochastic steady-state. But the central fact of life that makes financial economics interesting is that risk premia are not at all second order."

Our algorithm uses finite element methods. We define grids for the two state variables and we approximate the value function along the capital dimension by means of a low-degree spline. The stochastic process is approximated by a $6 \times 6$ Markov chain, along the lines of Rouwenhorst (1995). The fixed point of the Bellman equation (1) is computed by repeatedly iterating on the operator. When we compared the unconditional asset returns generated by our algorithm with those obtained by loglinearizing around the deterministic steady-state, we found sizeable differences even for low levels of risk aversion. Another sign that accuracy may be a greater issue when dealing with prices than when dealing with quantities is that, when iterating on the Bellman operator, quantities settle much earlier than prices. It should be clear, however, that these considerations do not necessarily generalize to other frameworks.

\section{The Case of Epstein-Zin Preferences}

Here we consider the case of $\theta=0$. The resulting specification of the utility function is known in the literature as Epstein-Zin. The stochastic discount factor is

$$
m\left(\varepsilon_{i} \mid k, \varepsilon\right)=\beta e^{\lambda(\gamma-1)}\left[\frac{c\left(k^{\prime}, \varepsilon_{i}\right)}{c(k, \varepsilon)}\right]^{\gamma-1}\left[\frac{v\left(k^{\prime}, \varepsilon_{i}\right)}{\mu\left(k^{\prime}, \varepsilon\right)}\right]^{\eta-\gamma}
$$

where

$$
\mu\left(k^{\prime}, \varepsilon\right)=\left[\sum_{i} \pi\left(\varepsilon_{i} \mid \varepsilon\right) v^{\eta}\left(k^{\prime}, \varepsilon_{i}\right)\right]^{1 / \eta} .
$$

\subsection{Calibration}

We borrow most of the parameter values from the real business cycle literature. The model period is one quarter. The income share of capital $(\alpha)$ is equal to 0.36. Following Cooley and Prescott (1995), we set $\lambda$ and $\varphi$ so that the yearly growth rates of population and per-capita output are $1.2 \%$ and $1.56 \%$, respectively. Once again following Cooley and Prescott (1995), the autocorrelation coefficient $\rho$ is set to 0.95 . The standard deviation $\sigma$ is chosen so that the model generates a standard deviation of output growth of about $1 \%$. 
The parameters $\gamma, \eta$, and $\iota$ are chosen to match the relative standard deviation of quarterly consumption growth, the quarterly expected risk-free rate, and the quarterly expected equity premium. Our targets are $0.5,0.252 \%$, and $1.893 \%$, respectively.

Simple computations show that the optimality conditions imply restrictions for the parameters $\beta$ and $\delta$ on the balanced growth path, in the deterministic version of our model. These conditions are

$$
\begin{aligned}
\delta & =\frac{y-c}{k}+1-e^{\lambda+\varphi}, \\
\alpha \frac{y}{k} & =\frac{e^{\lambda+\varphi}}{\beta^{*}}+\delta-1,
\end{aligned}
$$

where $\beta^{*} \equiv \beta e^{\varphi+\lambda \gamma}$ is the discount factor in Bellman Equation (1). Following other contributions in the the literature on asset pricing in production economies, such as Jermann (1998) and Danthine and Donaldson (2002), we decide to set $\delta=.025$, implying an annual depreciation rate of $10 \%$, and $\beta^{*}=0.99$. These values imply an annual capital-output ratio of 2.14, lower than most available estimates (Cooley and Prescott (1995) report a value of 3.32, when housing is accounted for), and a $12.7 \%$ investment-capital ratio at the annual frequency, higher than the US historical average of $7.6 \%$ reported by Cooley and Prescott (1995).

The calibration is summarized in Table 1. The plausibility of the parameters $\gamma$, $\eta$, and $\iota$ is assessed in Section 4. Notice that, as it is the case in Jermann (1998) and Boldrin, Christiano, and Fisher (2001), our values for $\beta^{*}, \varphi, \lambda$, and $\gamma$ imply that $\beta>1$. For $\beta>1$, a version of our model with no growth would not allow equilibria with positive interest rates. However, as shown by Kocherlakota (1990b) in the case of endowment economies, equilibria with positive interest rates may exist in growing economies, in spite of the fact that $\beta>1 .^{8}$

\begin{tabular}{cccccc}
\hline$\alpha$ & $\delta$ & $\lambda$ & $\varphi$ & $\beta$ & $\gamma$ \\
0.36 & 0.025 & 0.00387 & 0.00298 & 1.147 & -38.86 \\
\hline \hline$\eta$ & $\theta$ & $\xi$ & $\rho$ & $\sigma$ & $\iota$ \\
-17.53 & 0 & 1 & 0.95 & 0.0164 & 1.2153 \\
\hline
\end{tabular}

Table 1: Calibration with Epstein-Zin Preferences

\footnotetext{
${ }^{8}$ In the past, many scholars have manifested uneasiness with respect to discount rates greater than 1. A commonly used argument is that such an assumption implies that households prefer future consumption to current consumption. This is always true in the case of constant streams of consumption. It does not have to be true, however, in the case, like ours, of growing consumption. Finally, it is worth recalling that several econometric studies, among which Hansen and Singleton (1982) estimated $\beta$ to be significantly greater than 1.
} 


\subsection{Results: Unconditional Moments}

Recall that our parameterization is designed to match the ratio of the standard deviation of consumption growth to the standard deviation of output growth $\sigma_{C} / \sigma_{Y}$, the expected unconditional risk-free rate $\left(E\left(r^{f}\right)\right)$, and the expected unconditional equity premium $\left(E\left(r^{e}-r^{f}\right)\right)$. The purpose of this sub-section is to compare the model's predictions for other unconditional moments of asset returns, to their empirical counterparts. Notice that our target for the equity premium is higher than reported from most studies in the literature. The main reason is that we include the 1990's in our sample. ${ }^{9}$

\begin{tabular}{ccccccc}
\hline & $\sigma_{C} / \sigma_{Y}$ & $\sigma_{I} / \sigma_{Y}$ & $E\left(r^{f}\right)$ & $S t d\left(r^{f}\right)$ & $E\left(r^{e}-r^{f}\right)$ & $S t d\left(r^{e}\right)$ \\
\hline \hline Model & 0.501 & 2.516 & $0.250 \%$ & $2.96 \%$ & $1.889 \%$ & $12.16 \%$ \\
\hline Data & 0.499 & 2.647 & $0.252 \%$ & $0.834 \%$ & $1.893 \%$ & $7.694 \%$ \\
\hline
\end{tabular}

Table 2: Unconditional Moments with Epstein-Zin Preferences

We are not the first to consider the asset pricing implications of the stochastic growth model with power risk preferences and convex adjustment costs. The conclusion reached by Jermann (1998) is that with $\gamma=\eta=-9$, i.e. with a coefficient of relative risk aversion of 10 and an elasticity of intertemporal substitution of 0.1 , the model generates a counter-factually low annual risk-premium of just $0.26 \%$ and a counter-factually high risk-free rate of $3.36 \%$. These findings motivated him to consider internal habit instead. Internal habit increases the curvature of the utility function. This implies higher risk-aversion and lower intertemporal elasticity of substitution. The latter fact, together with convex adjustment costs, allows to raise the volatility of the stock return while keeping the standard deviation of consumption growth low. As Jermann very effectively puts it: "They (consumers) have to both care (about consumption smoothing), and be prevented from doing anything about it." Here we show that essentially the same result can be achieved with Epstein-Zin preferences, simply by raising the RRA coefficient beyond 10 and lowering the elasticity beyond $0.1 .^{10}$ Higher risk-aversion has the result of raising the equity premium and also the precautionary motive, thereby lowering the risk-free rate. At the same time, the elasticity of substitution will drop to a value that allows us to match the volatility of consumption growth while raising the standard deviation of stock returns at the

\footnotetext{
${ }^{9}$ Table 12 in the Appendix compares our unconditional moments with those reported by other papers in the literature on asset pricing in general equilibrium production economies.

${ }^{10}$ The plausibility of such assumption in the context of our model, is assessed in Section 4.
} 
same time. As the reader may expect, similar results can also be obtained under the restriction $\gamma=\eta$, i.e. in the case in which agents maximize expected discounted utility. We verify this conjecture in Section 3.5.

¿From Table 2, one can also appreciate that the model generates such a high expected equity premium at the price of a standard deviation of equity return that is substantially higher than in the data. Therefore, one may wonder what premium could the model generate if we required that standard deviation to be closer to its empirical counterpart. The answer to this question will be provided in Section 3.5. There we will show that, under the restriction $\gamma=\eta$, the model generates an equity premium essentially equal to that targeted by Mehra and Prescott (1985), with a standard deviation of equity return that is only slightly higher than in the data.

Where the model seems to miss completely the target is the standard deviation of the risk-free rate, which turns out to be about 3 times as large as in the data. This shortcoming, which is shared by the models with habit formation of Jermann (1998) and Boldrin, Christiano, and Fisher (2001), is due to the combination of a low elasticity of substitution (low $\gamma$ ) and rapidly increasing marginal adjustment costs (low ८). A low elasticity of substitution means that households are very eager to smooth consumption. In turn, this implies that the demand for bonds is very inelastic. A low value of $\iota$ means that adjustment costs are particularly effective in preventing consumption smoothing. This means that the productivity shocks imply wider shift of the bond demand schedule. Finally, since the supply of bonds is perfectly rigid, it follows that the risk-free rate must vary a lot.

\subsection{Results: Business-Cycle Properties of Asset Returns}

Figures 1 and 2 report impulse response functions for quantities and prices, respectively. The plots were obtained by averaging out the values generated by simulating the model for 200,000 runs of 250 periods each. In period 1 of each run, detrended capital is set equal to the mean of its unconditional equilibrium distribution, while the shock is set to the highest value in its grid. Statistics are expressed in percentage deviation from their unconditional means.

The response to the innovation in the shock has a half life which is much greater than that implied by more standard versions of the stochastic growth model. This difference, which is clearly due to the investment adjustment cost, also shows up in terms of greater persistence of output. While the autocorrelation of the process for $\varepsilon_{t}$ is only 0.95 , that of detrended output turns out to be 0.989 . 
The bottom-left panel of Figure 1 reproduces the path of the price of capital, i.e. the cost of diverting one more unit from current consumption to capital accumulation. In the absence of investment adjustment costs, it would be constant at 1 . In our case it is decreasing over time, as the progressive decline in the marginal product of capital calls for a decreasing pattern of investment. For the same reason, dividends drop on impact, and then grow back to their unconditional mean. The share price, which is the product of the price of capital and the capital stock, also jumps and then regresses to its unconditional mean. The two latter observations directly imply that the return on equity must drop on impact and then go back to its unconditional mean. They also imply that, consistently with the evidence, the price-dividend ratio is procyclical. Finally, the risk-free rate follows closely the pattern of consumption growth.
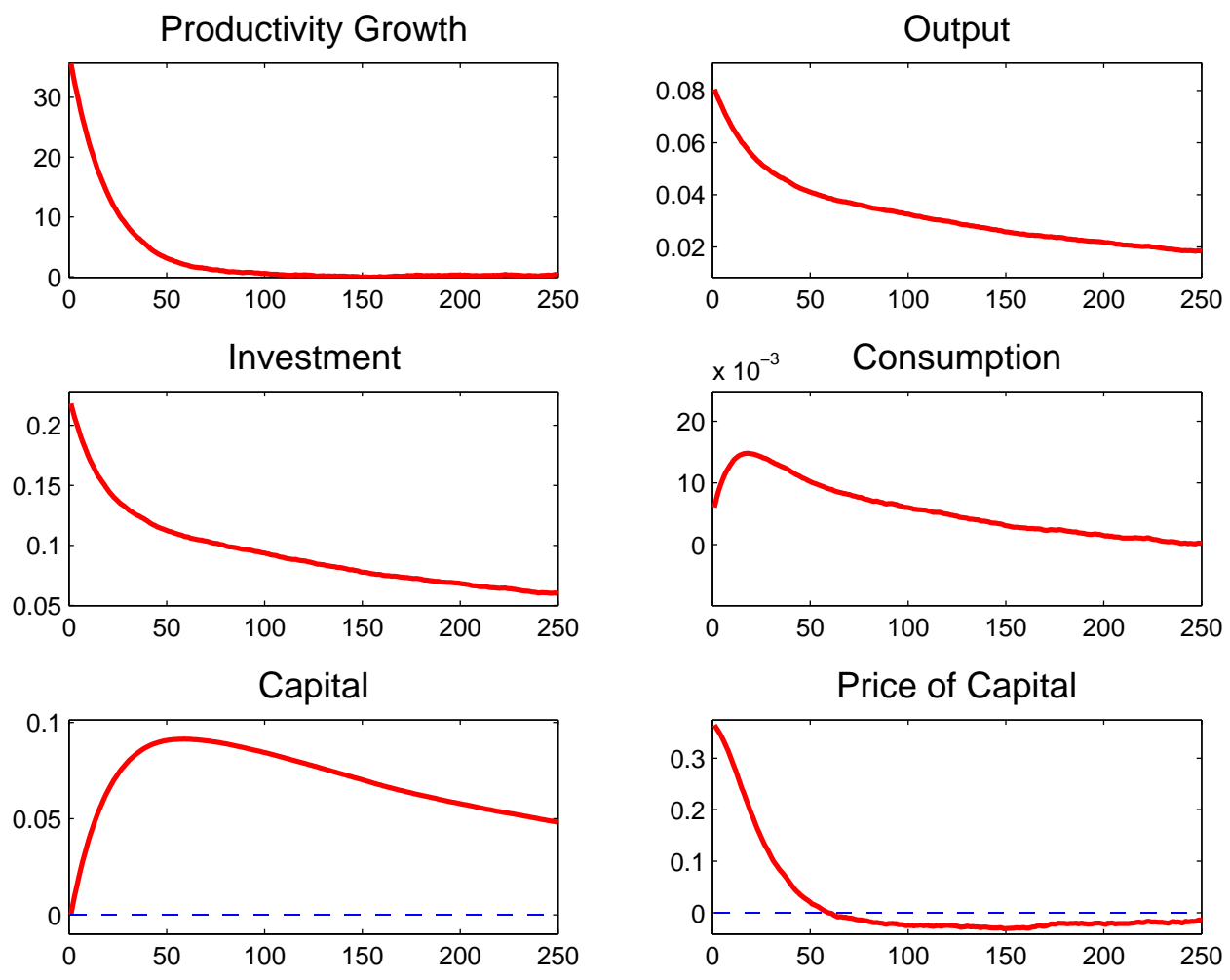

Figure 1: Impulse Responses: Quantities.

The business cycle properties of the model are summarized in Table 3, which reports the unconditional correlations between output growth, consumption growth, 

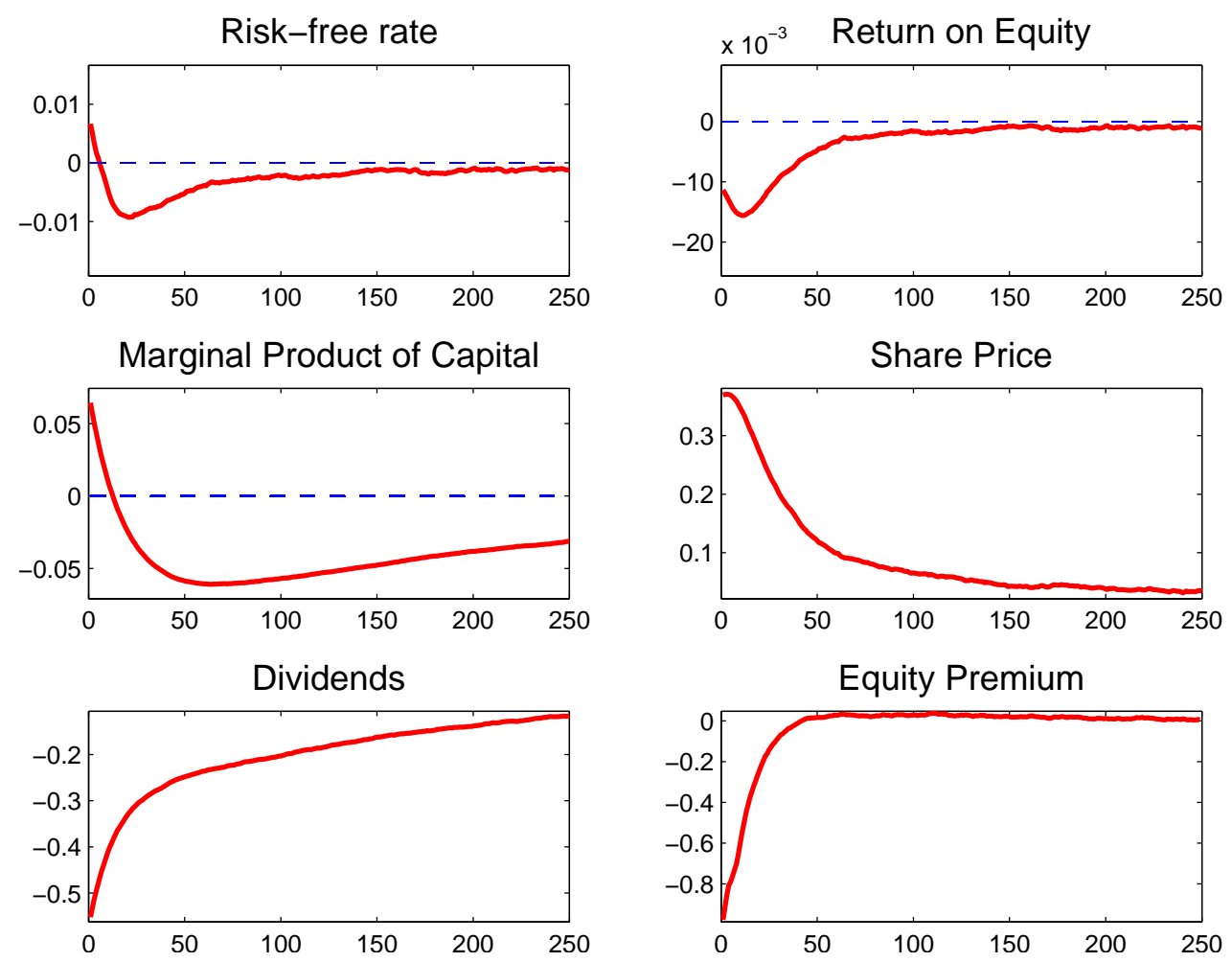

Figure 2: Impulse Responses: Prices.

and asset returns. On the one hand, the model does quite a good job in matching the correlation pattern of risk-free rate, stock return, and equity premium. The same can be said for the correlation between risk-free rate and output growth and for that between risk-free rate and consumption growth. On the other hand, it generates correlations between output growth and stock return and between consumption growth and stock return that are much larger than in the data. This feature is not that surprising, given that ours is a one-shock model.

\begin{tabular}{l|cc|cc|cc|cc} 
& \multicolumn{2}{|c|}{$c^{\prime} / c$} & \multicolumn{2}{c|}{$r^{f}$} & \multicolumn{2}{c|}{$r^{e}$} & \multicolumn{2}{c}{$r^{e}-r^{f}$} \\
\hline & Model & Data & Model & Data & Model & Data & Model & Data \\
\hline$y^{\prime} / y$ & 0.940 & 0.446 & 0.051 & -0.062 & 0.779 & 0.039 & 0.787 & 0.047 \\
$c^{\prime} / c$ & & & 0.132 & 0.0922 & 0.921 & 0.161 & 0.912 & 0.153 \\
$r^{f}$ & & & & & 0.224 & 0.187 & -0.014 & 0.0798 \\
$r^{e}$ & & & & & & & 0.971 & 0.994
\end{tabular}

Table 3: Unconditional Correlations

It's worth noticing that quantity dynamics is essentially invariant with respect to $\eta$, the parameter governing risk aversion. Hansen, Sargent, and Tallarini (1999) show 
that in the case of quadratic utility and linear constraints, this result holds exactly. ${ }^{11}$

\subsection{Results: Predictability of Asset Returns}

Every student of finance soon learns that stock prices, dividends, and returns are linked by an accounting identity. For any stock $i$,

$$
R_{t+1}^{i} \equiv\left(P_{t+1}^{i}+D_{t+1}^{i}\right) / P_{t}^{i}
$$

It follows that if the price of an asset is high today, agents must be expecting that either next period's price will be high, or the dividends will be high, or the rate of return will be low. Or a combination of these events. In turn, this means that, if stock prices are not explosive, a high price today must be associated with either low returns or high dividends in the future, or both.

Campbell and Shiller (1988) formalize the above argument, by log-linearizing the above identity and iterating forward, to obtain

$$
\log \left(P_{t}^{i} / D_{t}^{i}\right)=\frac{b}{1-\nu}+E_{t} \sum_{s=0}^{\infty} \nu^{s}\left[\log \left(D_{t+1+s}^{i} / D_{t}^{i}\right)-\log \left(r_{t+1+s}^{i}\right)\right],
$$

where $b$ and $\nu<1$ are linearization constants. Indeed, several authors, among which Campbell and Shiller (1988) and Fama and French (1988a,b), have shown that real stock returns, in particular at long horizons, are forecasted by the price-dividend ratio. However, price-dividend ratios do not forecast dividend growth. These phenomena are summarized in the columns labeled "Data" in Table 4, where we report the results of regressing cumulative stock returns and dividend growth at different horizons, on the current price-dividend ratio. As expected, the regression coefficients associated with cumulative returns are negative. Furthermore, their absolute values and their $R^{2}$ are increasing with the horizon. Dividend growth, instead, is essentially not forecastable by means of the price-dividend ratio. The figures reported in the columns labeled "Model" are computed using data obtained simulating the model. The pattern is very similar to the one just discussed. Stock returns are forecastable, and increasingly so as the horizon increases. Dividend growth, instead, is not.

The relation between current price-dividend ratio and future stock returns may be due to the predictability of the risk-free rate, the equity premium, or both. The evidence, summarized in Table 5, shows that the predictability of stock returns is

\footnotetext{
${ }^{11}$ This property has also the effect of dramatically reducing the computational burden. It allows us to proceed in two steps. First, we compute the locus of parameters $(\gamma, \iota)$ such that the model matches the relative standard deviation of consumption, for given $\eta$. Call this locus $\iota(\gamma)$. Then we look for the triple $[\eta, \gamma, \iota(\gamma)]$ such that the model matches exactly the remaining two moments.
} 
Table 4: Long-Horizon Regressions of Equity Returns and Dividend Growth

\begin{tabular}{cccccccccc}
\hline \hline Dependent Variables & \multicolumn{3}{c}{$r_{t, t+s}^{e}$} & \multicolumn{5}{c}{$D_{t+s} / D_{t}$} \\
& \multicolumn{2}{c}{ Model } & \multicolumn{2}{c}{ Data } & \multicolumn{3}{c}{ Model } & \multicolumn{2}{c}{ Data } \\
\hline Horizon (s) & Slope & $R^{2}$ & Slope & $R^{2}$ & Slope & $R^{2}$ & Slope & $R^{2}$ \\
1 & -.061 & 0.05 & -.115 & 0.08 & .0574 & .00 & -.031 & .05 \\
& $(-51.22)$ & & $(-2.18)$ & & $(2.73)$ & & $(-1.64)$ & \\
2 & -.1118 & 0.1 & -.22 & 0.14 & .6522 & .01 & -.059 & .05 \\
& $(-72.60)$ & & $(-3.04)$ & & $(18.42)$ & & $(-1.76)$ & \\
3 & -.155 & 0.14 & -.284 & 0.18 & .6681 & .01 & -.084 & .05 \\
& $(-88.74)$ & & $(-3.46)$ & & $(17.06)$ & & $(-1.74)$ & \\
5 & -.2208 & 0.20 & -.509 & 0.29 & 1.4357 & .00 & -.131 & .07 \\
& $(-110.59)$ & & $(-4.65)$ & & $(12.35)$ & & $(-1.96)$ & \\
7 & -.2686 & 0.24 & -.778 & 0.36 & 2.2512 & .01 & -.169 & .05 \\
& $(-125.23)$ & & $(-5.35)$ & & $(16.14)$ & & $(-1.68)$ & \\
\hline
\end{tabular}

Note: $t$ statistics in parenthesis. Specification: $x_{t, t+s}=a+b \log (P / D)_{t}+\epsilon_{t}$

Data sources: See Appendix A.

almost entirely due to time-variation in the expected equity premium. This confirms the finding of many others before us, among which Campbell (1999). Table 5 also shows that, in the case of our model, the opposite occurs. Differently from what happens in the data, the expected equity premium is essentially acyclical, and the predictability of stock returns is due to time-variation in the risk-free rate. These findings are not surprising. One the one hand, the model generates a much higher volatility of the risk-free rate than in the data. On the other hand, given that riskaversion and the volatility of stock returns is acylical by construction, there is no reason to expect expected equity premia to to be counter-cyclical.

Table 5: Long-Horizon Regressions of Equity Premia and Risk-Free Rate

\begin{tabular}{cccccccccc}
\hline \hline Dependent Variables & \multicolumn{3}{c}{$r_{t, t+s}^{e}-r_{t, t+s}^{f}$} & \multicolumn{5}{c}{$r_{t, t+s}^{f}$} \\
& \multicolumn{2}{c}{ Model } & \multicolumn{2}{c}{ Data } & \multicolumn{2}{c}{ Model } & \multicolumn{2}{c}{ Data } \\
\hline Horizon (s) & Slope & $R^{2}$ & Slope & $R^{2}$ & Slope & $R^{2}$ & Slope & $R^{2}$ \\
1 & -.0054 & .00 & -.117 & 0.08 & -.0556 & 0.2 & .002 & .00 \\
& $(-4.25)$ & & $(-2.27)$ & & $(-109.81)$ & & $(.18)$ & \\
2 & -0.0088 & .00 & -.219 & 0.15 & -.1030 & 0.2 & -.001 & .00 \\
& $(-4.86)$ & & $(-3.13)$ & & $(-110.01)$ & & $(-.03)$ & \\
3 & -.0111 & .00 & -.28 & 0.19 & -.144 & 0.19 & -.004 & .00 \\
& $(-4.96)$ & & $(-3.60)$ & & $(-109.02)$ & & $(-.17)$ & \\
5 & -.0097 & .00 & -.484 & 0.31 & -21.11 & 0.18 & .04 & .01 \\
& $(-3.37)$ & & $(-4.78)$ & & $(-105.52)$ & & $(-.69)$ & \\
7 & -.0047 & .00 & -.712 & 0.36 & -.2639 & 0.17 & -.066 & .03 \\
& $(-1.39)$ & & $(-5.29)$ & & $(-101.23)$ & & $(-1.33)$ & \\
\hline
\end{tabular}

Note: $t$ statistics in parenthesis. Specification: $x_{t, t+s}=a+b \log (P / D)_{t}+\epsilon_{t}$

Data sources: See Appendix A. 
Routledge and Zin (2004) have shown that, in the case of a Mehra-Prescott economy, generalized disappointment aversion generates time-varying risk premia. In Section 5 we will ask whether this property extends to our framework, and, in the affirmative case, whether it implies predictability of the equity premium to the extent present in the data.

\subsection{The Case of Expected Discounted Utility}

Here we characterize the equilibrium allocation under the restriction $\eta=\gamma$. This is the popular scenario in which agents maximize expected discounted utility. The stochastic discount factor is

$$
m\left(\varepsilon_{i} \mid k, \varepsilon\right)=\beta e^{\lambda(\gamma-1)}\left[\frac{c\left(k^{\prime}, \varepsilon_{i}\right)}{c(k, \varepsilon)}\right]^{\gamma-1} .
$$

The only innovation in the calibration procedure is that we now have only two free parameters, $\gamma$ and $\iota$, which we set in order to match $\sigma_{C} / \sigma_{Y}$ and $E\left(r^{f}\right)$. The resulting values are $\iota=1.25$ and $\gamma=-31.2$.

Table 6 shows the results of the numerical experiment. Although the model does not match the post-war mean equity premium, it is able to generate an annual value of about $6.11 \%$, which is essentially the one targeted by Mehra and Prescott (1985) and several other studies after them. The volatility of the risk-free rate and stock return are lower than in the general EZ case, and they are closer to their empirical counterparts. Let's briefly consider why this is the case.

Our calibration procedure is such that the volatility of consumption growth is kept constant across parameterizations. For given process of consumption growth, moving from the EZ case to the EU case while preserving the expected risk-free rate implies decreasing $\eta$ and increasing $\gamma$. It turns out that this leads to a decrease in the precautionary saving motive and therefore to an increase in the volatility of consumption growth. The latter is lowered back to its target level by increasing $\iota$, the elasticity parameter in the adjustment cost function. In fact, slower-rising adjustment costs imply a higher volatility of investment growth. By the resource constraint, this also means lower volatility of consumption growth. The volatility of the relative price of capital also drops, determining a decrease in the first and second moments of the equity return.

We do not show the impulse response functions and the results of the predictability regressions, as they are very close to those obtained in the case of general Epstein-Zin preferences. 


\begin{tabular}{ccccccc}
\hline & $\sigma_{C} / \sigma_{Y}$ & $\sigma_{I} / \sigma_{Y}$ & $E\left(r^{f}\right)$ & $S t d\left(r^{f}\right)$ & $E\left(r^{e}-r^{f}\right)$ & $S t d\left(r^{e}\right)$ \\
\hline \hline Model & 0.503 & 2.387 & $0.251 \%$ & $2.338 \%$ & $1.527 \%$ & $9.615 \%$ \\
\hline Data & 0.499 & 2.647 & $0.252 \%$ & $0.834 \%$ & $1.893 \%$ & $7.694 \%$ \\
\hline
\end{tabular}

Table 6: Unconditional Moments with Expected Discounted Utility

\section{Assessing Parameter Values}

We now assess the plausibility of the values for the parameters $\gamma, \eta$, and $\iota$, which govern elasticity of substitution, risk aversion, and adjustment costs, respectively.

\subsection{Adjustment Costs}

As argued above, investment adjustment costs are needed to produce variation in the price of capital, a necessary condition to generate a substantial volatility of the share price. As a matter of fact, essentially all studies in the literature on asset pricing in production economy assume the existence of such costs or other rigidities that impede the smooth adjustment of capital to shocks. ${ }^{12}$ The question is whether the model produces overidentifying restrictions that can be used to assess how reasonable is the value for the parameter $\iota$ implied by our calibration procedure. Under our assumptions, marginal Tobin's $q$ equals average $q$. Therefore, it is natural to think of validating the model by comparing the elasticity of the investment rate with respect to $q$ to its estimated counterpart. In our model, $q$ equals the price of capital and the elasticity is simply:

$$
\frac{d \log (i / k)}{d \log (q)}=\frac{d(i / k)}{d P_{k^{\prime}}} \frac{P_{k}^{\prime}}{i / k}=\frac{1}{i / k} \frac{1+\chi\left(\frac{i}{k}\right) \iota\left|\frac{i}{k}+(1-\delta)-\psi\right|^{\iota-1}}{\iota(\iota-1)\left|\frac{i}{k}+(1-\delta)-\psi\right|^{\iota-2}},
$$

where $\chi(i / k)=1$ if $(i / k)>\psi-(1-\delta)$, and $\chi(i / k)=-1$ otherwise. In the stationary distribution, the point elasticity ranges between 0 and 3 , with a mean of 0.77 .

It is well-known that all attempts to estimate the elasticity using aggregate data have given disappointing outcomes. Typically, the estimates are not significantly different from zero, and the variation in aggregate $q$ accounts for a risible fraction of the variation in investment rates. ${ }^{13}$ In the last ten years or so, several authors have studied the relation between investment and Tobin's $q$ using firm-level data. In

\footnotetext{
${ }^{12}$ This is the case for Jermann (1998), Boldrin, Christiano, and Fisher (2001), Danthine and Donaldson (2002), Guvenen (2005), and Croce (2006).

${ }^{13}$ We refer to studies, such as von Furtstenburg (1977), where the investment to capital ratio is gross aggregate investment divided by an estimate of the aggregate capital stock, and $q$ is the ratio of market capitalization to the capital stock.
} 
particular, we refer to the work of Eberly (1997), who took advantage of the Global Vantage dataset, and Barnett and Sakellaris (1998) and Abel and Eberly (2002), who worked with Compustat data. One of the main lessons learned from them is that the relationship between investment and $q$ is highly non-linear. A corollary is that information on the cross-sectional distribution of $q$ can be used to improve the predictive power of investment equations. For example, when they estimate aggregate elasticity by computing the increase in total investment implied by a $1 \%$ increase in $q$ for all firms, Barnett and Sakellaris (1998) obtain a point estimate of 0.84. When controlling for higher moments of the distribution of $q$, Eberly (1997) finds that regressing $\log \left(\sum_{i} I_{i} / K_{i}\right)$ on $\sum_{i} q_{i}$, she obtains a point estimate of 0.62 , with a $R^{2}$ of 0.08. Regressing $\sum_{i} \omega_{i} \log \left(I_{i} / K_{i}\right)$ over $\sum_{i} \omega_{i} q_{i}$ (with $\omega_{i}=K_{i} / \sum_{i} K_{i}$ ) yields a coefficient estimate of 0.72, with $R^{2}$ of 0.38. Interestingly, Abel and Eberly (2002) also estimate that adjustment costs amount to $1.1 \%$ of the cost of investment in manufacturing, and 9.7\% in non-manufacturing sectors. In the case of our model, the mean value is about $1.59 \%$.

While the findings we have just summarized cannot be used for direct falsification of our model, they suggest that its implications for the magnitude of adjustment costs and the elasticity of investment to Tobin's $q$ are hardly out of line.

\subsection{Elasticity of Intertemporal Substitution}

Our calibration also implies a value for the elasticity of intertemporal substitution that is unusually low for the macroeconomics literature. However, although very far from the unitary value that we are used to see assumed in macroeconomic models, an intertemporal elasticity of substitution of about $1 / 39$ falls in the confidence interval of several econometric studies, among which Hall (1988).

Campbell and Cochrane (1999) pointed out a further restriction on the value of the intertemporal elasticity of substitution, by considering its implication for the crosscountry variation of interest rates. A low elasticity may imply a counterfactually high variation. This can be easily seen in the case of an endowment economy with $\gamma=\eta$ and i.i.d. lognormal consumption growth with mean $\lambda$ and standard deviation $\sigma$. In that case, one can write

$$
\log \left(r_{t}^{f}\right)=\log (\beta)+(1-\gamma) \lambda-(1-\gamma)^{2} \frac{\sigma^{2}}{2} .
$$

Campbell and Cochrane (1999) argue that if preferences were the same across countries, in absence of international capital flows, a very low $\gamma$ may translate minimal 
differences in growth rates $\lambda$ into large differences in risk-free rates. Whether it will or not, depends on the cross-country relation between first and second moment of consumption growth. Since countries with high consumption growth rates also tend to have lower standard deviation of consumption growth, the precautionary motive will work towards reducing the dispersion in interest rates. Without considering actual

data, it is not possible to draw a conclusion on the net effect. Kandel and Stambaugh (1991) report that during the period 1957-1987, average real consumption growth was $8.2 \%$ in South Korea and $3.2 \%$ in the United States. They go on to argue that, under the lognormality assumption and with an elasticity of $1 / 29$, a $4 \%$ difference in the volatility of consumption growth would make the simple model consistent with the data. They argue that the actual measured difference was not that far, at $2.1 \%$.

\subsection{Risk Aversion}

Since the appearance of Mehra and Prescott (1985), the main objective of most contributions to the asset pricing literature has been to lower the level of risk-aversion needed to attain an unconditional expected equity premium consistent with the data. As pointed out by Kocherlakota (1996), this was - and still is - due to the fact that most economists believe a coefficient of relative risk aversion higher than 10 to be highly implausible.

Indeed, during the last thirty years or so there have been quite a few studies that showed how popular models of economic behavior imply a rather low coefficient of relative risk aversion. These studies have contributed to generate the belief that individuals are not nearly as risk-averse as it is needed by most asset pricing models to generate sizeable risk premia. However, as also acknowledged by Mehra and Prescott (1985) and Kocherlakota (1996), the conclusions of all of these studies have been successfully challenged. For example, among the arguments in support of an upper bound of 10, Mehra and Prescott (1985) cite the work of Kydland and Prescott (1990) and Friend and Blume (1975). Kydland and Prescott (1990) find that only RRA coefficients between 1 and 2 allow their model to replicate the observed relative variabilities of detrended investment and consumption. It is clear though, that such result is model-specific. Our work, for example, shows that it is possible to achieve the same result with higher risk-aversion. Friend and Blume (1975) argue that a low RRA coefficient is needed for models of portfolio allocation to generate allocations of wealth across risky and riskless assets that is not grossly counterfactual. There are at least two important issues that detract from the relevance of this result. Kandel and 
Stambaugh (1991) convincingly argue that it obtains in endowment economies under time-additive expected utility and i.i.d. consumption growth, but does not generalize to other settings. Kocherlakota (1990a) shows that it vanishes if one uses proxies for the market portfolio that are broader than the stock market. For some time, the most compelling argument against higher risk-aversion has been what is known as the riskfree rate puzzle. Weil (1989) showed that, in an endowment economy where agents maximize expected discounted utility, the low elasticity of intertemporal substitution implied by high risk aversion also induces a conterfactually high risk-free rate. This argument, however, essentially lost all of his bite when Epstein and Zin (1990b) showed how to easily disentangle attitude towards risk from attitude towards growth. Furthermore, the results illustrated in the previous sections of this paper show that for our model, as well as for Jermann (1998)'s and Boldrin, Christiano, and Fisher (2001)'s, a low elasticity of substitution is actually a necessary condition for success.

Our opinion is that the debate on the plausibility of different levels of the RRA coefficient is misleading. The main reason is that it somewhat disregards the simple fact that all commonly used measures of the attitude towards risk, among which also the RRA coefficient, are local. Or that, in other words, agents' attitude towards risk depends, possibly in a dramatic way, on the variance of the bets they face. ${ }^{14}$ Regardless of her risk preferences, an agent's relative risk aversion is defined as the amount she would pay in order to avoid a multiplicative atemporal bet. This means that, in general, relative risk aversion measures must be indexed by the lottery's probability distribution. The simple calculations shown later in Section 5 remind us that the commonly used RRA coefficient is nothing else but the relative risk aversion that obtains for simple bets of infinitely small variance, in the case of expected utility.

We see two ways of assessing the relative risk aversion implied by a given model. First, we can ask whether the relative risk aversion computed at the "equilibrium bets" is at odds with experimental or direct empirical evidence. That is, we can investigate the plausibility of the implied relative risk aversion, given the risks implied by the model. We have computed this measure in the case of our framework. For given pair $(k, \varepsilon)$, and regardless of the shape of risk preferences, our agent faces a bet over the lottery $\left\{v\left[k^{\prime}(k, \varepsilon), \varepsilon_{i}\right], \pi\left(\varepsilon_{i} \mid \varepsilon\right)\right\}_{i=1}^{n}$, where $n$ is the number of values for the productivity shock. Our measure of risk-aversion is the value $P(k, \varepsilon)$ such that:

$$
[1-P(k, \varepsilon)] \sum_{i} \pi\left(\varepsilon_{i} \mid \varepsilon\right) v\left[k^{\prime}(k, \varepsilon), \varepsilon_{i}\right]=\mu\left[v\left(k^{\prime}, \varepsilon^{\prime}\right)\right] .
$$

\footnotetext{
${ }^{14}$ To our knowledge, Kandel and Stambaugh (1991) and Epstein and Zin (1990a) are the first to use this argument in the asset pricing literature.
} 
That is, the agent would be indifferent between the lottery and a sure amount equal to the fraction $1-P(k, \varepsilon)$ of its expected value. In Table 7 we report the values $P(k, \varepsilon)$ (expressed as a percentage of the lottery's expected value) that obtain for a given value of the shock $\varepsilon$ (the third, out of six) and for three levels of the detrended per-capita capital stock: the lowest in the ergodic set, the mean of the distribution, and the highest in the ergodic set, respectively. The columns labeled C.V. report our measure of risk: the coefficient of variation of the lotteries, expressed in percentage of their expected values. The first column refers to the case of Epstein-Zin preference under consideration here. The other two, to the case of disappointment aversion to be discussed in Section 5 .

Table 7: Implied Equilibrium Risk Aversion (in percentage points)

\begin{tabular}{ccccccc}
\hline \hline & \multicolumn{2}{c}{$E Z$} & \multicolumn{2}{c}{$D A$} & \multicolumn{2}{c}{$G D A$} \\
\hline$k$ & R.A. & C.V. & R.A. & C.V. & R.A. & C.V. \\
Low & .019 & 0.40 & .009 & 0.39 & .023 & .37 \\
Medium & .004 & 0.22 & .005 & 0.21 & .00079 & .24 \\
High & .002 & 0.13 & .003 & 0.13 & .0001 & .13 \\
\hline \hline
\end{tabular}

It appears that the risks faced by the agent are rather small. In the EZ case, at the mean of the distribution of capital the standard deviation is equal to only $0.22 \%$ of the lottery's expected value. In order to avoid the lottery and replace it with a sure amount, the agent would be willing to give up $0.004 \%$ of her expected value. Notice that any value $v(k, \varepsilon)$ could be implemented by a constant sequence of detrended consumption $c_{t}=v(k, \varepsilon)\left[1-\beta e^{\varphi+\lambda \gamma}\right]^{1 / \gamma}$. Therefore, the coefficient of variations and the risk-aversion measures can be recast as percentages of such constant consumption equivalent. For the parameter values adopted in Section 3, we have that $\left[1-\beta e^{\varphi+\lambda \gamma}\right]^{1 / \gamma}=1.125814$. For the sake of illustration, consider an agent with an expected utility of 22,206 . This is the same level of utility that would be generated by a constant stream of consumption equal to 25,000 . If the payoffs of the lottery $v\left[k^{\prime}(k, \varepsilon), \varepsilon_{i}\right]$ were to be implemented by constant consumption sequences, the coefficient of variation in terms of equivalent per-period consumption would be about 55. In order to avoid this risk, the agent would be willing to give up 1.0 units of consumption. Is it too much? Too little? Based on personal introspection, Cochrane (1997) does not find it unreasonable for a household earning $\$ 50,000$ per year to be willing to pay 25 cents in order to avoid a bet involving the gain or loss of $\$ 10$ with even probability. This leads us to conjecture that, most likely, he would not find 
the behavior of our agent to be unreasonable either. Unfortunately, the literature on the direct estimation of risk aversion is still fairly limited. Some of the studies suffer from the lack of background information about the subjects of the study. Others, from the fact that their results depend on the answers to hypothetical questions. Dohmen, Falk, Huffman, Sunde, Schupp, and Wagner (2005) gathered data about attitude towards risk by confronting 22,000 individuals with a series of choices among hypothetical lotteries. ${ }^{15}$ Unfortunately for us, they do not report their estimates by variance classes. They assume that agents are expected utility maximizers, and report that most agents have a relative risk aversion coefficient between 5 and 10. However, a non-negligible fraction of subjects displays a coefficient greater than 20.

A second way of assessing relative risk aversion is implied by the assumption of universality of risk preferences. That is, by the requirement that an agent's attitude towards risk is described by the same preference relation, regardless of the risk she faces. It has been pointed out that this criterion constitutes a problem for expected utility. ${ }^{16}$ Since under expected utility a bet's variance has only a second-order effect on risk-aversion, individuals are essentially risk-neutral when faced with low risk, for a very large range of RRA coefficients. The implication is that RRA coefficients that generate realistic levels of risk aversion for small risk, also generate implausibly large risk aversion with respect to larger risks. This shortcoming, very effectively illustrated in Rabin (2000), also applies to our framework. Even though the relative risk aversion of an EZ agent with with $\eta=-17.53$ is plausible at the risk levels implied by our model's equilibrium, the same agent will display unreasonable risk aversion when facing considerably greater risks. The literature on decision theory under uncertainty pointed out that the issue we have just illustrated is much less of a problem when risk preferences feature first-order risk aversion. This is yet another reason why it is of interest to analyze a version of our model in which agents are disappointment averse. We now turn to that. Our digression on risk aversion will continue in Section 5.2.

\footnotetext{
${ }^{15} \mathrm{~A}$ strength of their work is that they have rather accurate information about gender, age, and parental background of the respondents. A further strength is that they validate the survey's results by means of an experiment implying actual payments. The problem is that while the hypothetical questions allowed for arbitrary variance, funding constraints implied that the experiments were limited to low-variance lotteries.

${ }^{16}$ See for example Kandel and Stambaugh (1991), Epstein and Zin (1990a), and Rabin (2000).
} 


\section{Disappointment Aversion}

In this section we consider the case of disappointment aversion preferences due to Gul (1991). Before us, Epstein and Zin (2001), Routledge and Zin (2004) and Bonomo and Garcia (1994) have studied the asset pricing implications of this preference specification in endowment economies. To our knowledge, this is the first attempt at modeling it in a production economy. The reader that is familiar with its basic properties is advised to jump to the start of section 5.1.

In most applied work in economics, agents choose among risky outcomes (lotteries over simple events) by evaluating each of them according to the expected utility criterion. According to this paradigm, the certainty equivalent $\mu$ of a lottery over a finite set of payoffs $\left\{x_{1}, x_{2}, \ldots, x_{N}\right\}$ satisfies

$$
u(\mu)=\sum_{i=1}^{N} \pi_{i} u\left(x_{i}\right)
$$

where $\pi_{i} \geq 0, \sum_{i=1}^{N} \pi_{i}=1$, is the probability of event $i$ and $u$ is an increasing and continuous function. The preference relation over lotteries represented by this utility specification is known to satisfy the axioms of monotonicity, completeness, transitivity, continuity, and independence. The latter has repeatedly come under attack, as experimental studies have found an increasing number of instances in which individuals' decision making appears to violate it. Perhaps the most famous of these violations is that known as the Allais Paradox.

Decision theorists have therefore sought to identify preference relations that satisfy a weaker version of the independence axiom. Here we consider the work of Faruk Gul. Gul (1991) defines as disappointing those outcomes that lie below a lottery's certainty equivalent. His weak independence axiom requires independence only for lotteries that are disappointment-comparable. Gul shows that the preference relation satisfying this axiom, along with those named above, can be represented by the certainty equivalent $\mu$ that solves

$$
u(\mu)=\sum_{i=1}^{N} \pi_{i} u\left(x_{i}\right)-\theta \sum_{x_{i} \leq \mu} \pi_{i}\left[u(\mu)-u\left(x_{i}\right)\right] .
$$

Outcomes below the certainty equivalent receive a greater weight in the computation of overall utility. Such weight depends positively on the parameter $\theta$ and on the distance from the certainty equivalent itself. Notice that $\mu$ appears on both sides of the above condition, and therefore must be determined together with the set of disappointing states. It is sometimes handy to express $\mu$ as the following weighted 
average:

$$
u(\mu)=\sum_{i=1}^{N} \tilde{\pi}_{i} u\left(x_{i}\right), \quad \tilde{\pi}_{i}=\pi_{i} \frac{1+\theta \times I\left(x_{i}, \mu\right)}{1+\theta \sum_{\left(x_{i} \leq \mu\right)} \pi_{i}},
$$

where $\sum_{i}^{N} \tilde{\pi}_{i}=1$ and $I\left(x_{i}, \mu\right)$ is an indicator function that takes value 1 if $x_{i} \leq \mu$ and 0 otherwise. This formulation makes it clearer that under DA the attitude towards risk not only depends on the curvature of $u$, but also on the value of $\theta$. For the sake of illustration, consider the case of $N=2$. In Figure 3 we have pictured the qualitative behavior of indifference curves, in the cases of expected utility $(\theta=0)$ and disappointment aversion $(\theta>0)$. It is important to notice that, contrary to the expected utility case, under disappointment aversion the indifference curve is not differentiable at the certainty equivalent. The kink reflects what Segal and Spigal (1990) call first-order risk aversion, as opposed to second-order risk aversion, which characterizes expected utility. The difference between first- and second-order risk aversion can be appreciated by computing the effect of $\theta$ on relative risk aversion, i.e. on the amount $P$ (the risk premium) that an agent is willing to pay in order to avoid a given bet. ${ }^{17}$ Consider the following example. For some $\kappa \geq 0$, let an agent endowed with wealth $\omega_{0}$ consider an investment opportunity that pays $w_{0}(1+\kappa)$ and $w_{0}(1-\kappa)$ with equal probabilities. With disappointment aversion, the risk-premium associated with $\kappa, P(\kappa)$, solves

$$
\frac{1+\theta}{2+\theta} u\left[w_{0}(1-\kappa)\right]+\frac{1}{2+\theta} u\left[w_{0}(1+\kappa)\right]=u\left[w_{0}(1-P(\kappa))\right], \quad \kappa>0
$$

and satisfies $P(0)=0$. In a neighborhood of $\kappa=0$, we have that

$$
P(\kappa)=P(0)+\frac{d P}{d \kappa} d \kappa+\frac{1}{2} \frac{d^{2} P}{d \kappa^{2}} d \kappa^{2}=\frac{\theta}{2+\theta} d \kappa-\frac{1}{2} \frac{u^{\prime \prime}\left(w_{0}\right) w_{0}}{u^{\prime}\left(w_{0}\right)}\left[\frac{4(1+\theta)}{(2+\theta)^{2}}\right] d k^{2} .
$$

If the utility function is isoelastic with $\frac{u^{\prime \prime}\left(w_{0}\right) w_{0}}{u^{\prime}\left(w_{0}\right)}=\eta-1$, we can write

$$
P(\kappa)=\frac{\theta}{2+\theta} d \kappa+\frac{1}{2}(1-\eta)\left[\frac{4(1+\theta)}{(2+\theta)^{2}}\right] d k^{2},
$$

For $\theta>0$, an increase in $\kappa$, i.e. an increase in risk, has a first-order effect on the risk premium. This is why in this case we talk of first-order risk aversion. In the case of expected utility $(\theta=0)$ instead, risk has only a second-order effect, as we obtain the familiar expression $P(\kappa)=[(1-\eta) / 2] d k^{2}$. This is why $\left|\frac{u^{\prime \prime}\left(w_{0}\right) w_{0}}{u^{\prime}\left(w_{0}\right)}\right|=1-\eta$ is known as the de Finetti-Arrow-Pratt coefficient of relative risk-aversion.

\footnotetext{
${ }^{17}$ Here we focus on multiplicative bets, but similar arguments can be made for additive bets. For an accessible review of the definition and measurement of risk aversion, see Chapter 2 of Gollier (2001).
} 


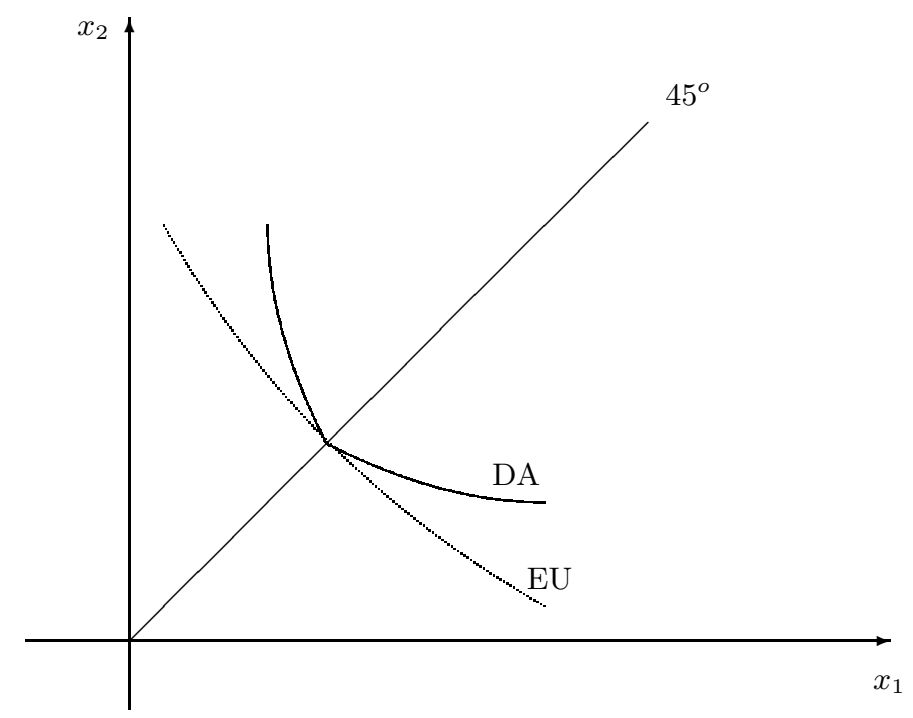

Figure 3: Indifference curves.

\subsection{Asset Returns}

In the case of disappointment aversion, the stochastic discount factor takes the following form:

$$
m\left(\varepsilon_{i} \mid k, z\right)=\beta e^{\lambda(\gamma-1)} \frac{1+\theta I\left(k^{\prime}, \varepsilon_{i}, \mu\right)}{1+\theta \sum_{i} \pi\left(\varepsilon_{i} \mid \varepsilon\right) I\left(k^{\prime}, \varepsilon_{i}, \mu\right)}\left[\frac{c\left(k^{\prime}, \varepsilon_{i}\right)}{c(k, \varepsilon)}\right]^{\gamma-1}\left[\frac{v\left(k^{\prime}, \varepsilon_{i}\right)}{\mu\left(k^{\prime}, \varepsilon\right)}\right]^{\eta-\gamma},
$$

where $I\left(k^{\prime}, \varepsilon_{i}, \mu\right)=1$ if $v\left(k^{\prime}, \varepsilon_{i}\right) \leq \mu$, and $I\left(k^{\prime}, \varepsilon_{i}, \mu\right)=0$ otherwise.

We decide to set $\eta=0$, assign to $\iota$ and $\gamma$ the values obtained in the calibration of the EZ model, and pick $\theta$ in order to minimize the distance between unconditional mean risk-free rate, unconditional equity premium, and the ratio of the standard deviation of consumption growth to the standard deviation of output growth from their respective targets. The value we obtain is $\theta=0.133$.

We follow this route, instead of re-calibrating the model, in order to point out the existence of an almost exact one-to-one correspondence between the parameters $\eta$ and $\theta$. That is, keeping all other parameters unchanged, for every value of $\eta$ (in a wide range) there exists a value of $\theta$ such that the DA model yields predictions that are very similar to those of the EZ model with that $\eta$. Table 8 reports the implied values for the second moment of risk-free rate and return on equity, and for the mean equity premium. The results are indeed very close to those obtained under Epstein-Zin preferences. The same can be said of the impulse response functions and of the correlations documented in Table 3. As we will see, however, the two 
specifications have radically different implications for the attitude towards risk, for levels of uncertainty different from those implied by the equilibrium of our model.

\begin{tabular}{ccccccc}
\hline & $\sigma_{C} / \sigma_{Y}$ & $\sigma_{I} / \sigma_{Y}$ & $E\left(r^{f}\right)$ & $S t d\left(r^{f}\right)$ & $E\left(r^{e}-r^{f}\right)$ & $\operatorname{Std}\left(r^{e}\right)$ \\
\hline \hline Model & 0.492 & 2.525 & $0.255 \%$ & $3.03 \%$ & $1.836 \%$ & $12.487 \%$ \\
\hline Data & 0.499 & 2.647 & $0.252 \%$ & $0.834 \%$ & $1.893 \%$ & $7.694 \%$ \\
\hline
\end{tabular}

Table 8: Unconditional Moments - Disappointment Aversion

As it was the case for the preference specifications considered in previous sections, even under disappointment aversion the price-dividend ratio does not predict future levels of the equity premium. This is not surprising given that, even under DA, risk-aversion is essentially acyclical by construction.

\subsection{Reconsidering Risk Aversion}

In Section 3 we acknowledged that most economists would find a value of $\eta=-17.53$, necessary for the EZ model to match the average historical equity premium, to be implausible. We have argued, however, that the emphasis on a local measure such as the coefficient of relative risk aversion is misleading. In fact, in the case of our model, the relative risk aversion measured at the equilibrium risk does not seem to be excessive. We also noted that a value of $\eta=-17.53$ could still be problematic, as it would imply a much higher relative risk aversion for higher risks. Here we document that this criticism does not apply to the DA model.

Table 7 shows that the models with expected utility and disappointment aversion, calibrated to match the same asset pricing moments, generate about the same riskaversion for equilibrium bets. However, they imply very different levels of risk aversion for greater risks. This phenomenon is illustrated in Figure 4, which plots the loci of $1-\eta$ and $\theta$ such that the EU and DA models generate the same level of relative risk aversion, for simple bets with different risks. To be precise, we have considered a simple atemporal bet that pays $1-\kappa$ or $1+\kappa$ with equal probability, similarly to what we have done in Section 4. We then identified, for given $0<\kappa<1$, the set of pairs $(\theta, \eta)$ such that

$$
\frac{1+\theta}{2+\theta}(1-\kappa)+\frac{1}{2+\theta}(1+\kappa)=\left[\frac{1}{2}(1-\kappa)^{\eta}+\frac{1}{2}(1+\kappa)^{\eta}\right]^{1 / \eta} .
$$

The left-hand side is the certainty equivalent of the bet for a GDA agent with disappointment aversion parameter $\theta, \eta=1$ (no curvature in the Bernoulli utility function), 
and $\xi=1$. The right-hand side is the certainty equivalent for an EU agent with relative risk-aversion coefficient $1-\eta$. For a few values of $\kappa$, which also equals the coefficient of variation of the bet, Figure 4 plots the loci of pairs $(\theta, 1-\eta)$ that satisfy the above condition. Notice that the slope of the loci is decreasing in $\kappa$. The larger the risk, the higher the value of $\theta$ that (under DA) produces the same relative risk aversion generated by a given $\eta$ (under EZ). The relative risk-aversion coefficient that is equivalent to any given value of $\theta$ is higher, the lower the risk. The second column of Table 7 indicates that at the mean of the distribution of capital, our calibration of the model with Epstein-Zin preferences generates a coefficient of variation of $0.22 \%$. Figure 4 shows that in the case of the atemporal lotteries considered here, a disappointment averse agent displaying the same relative risk aversion at that risk must have $\theta \approx 0.04$. For a coefficient of variation 100 times higher, i.e. $\kappa=0.22$, the relative risk aversion of the same EU agent goes through the roof. However, the DA agent exhibits an attitude towards risk close to that of an EU agent with logarithmic utility! ${ }^{18}$

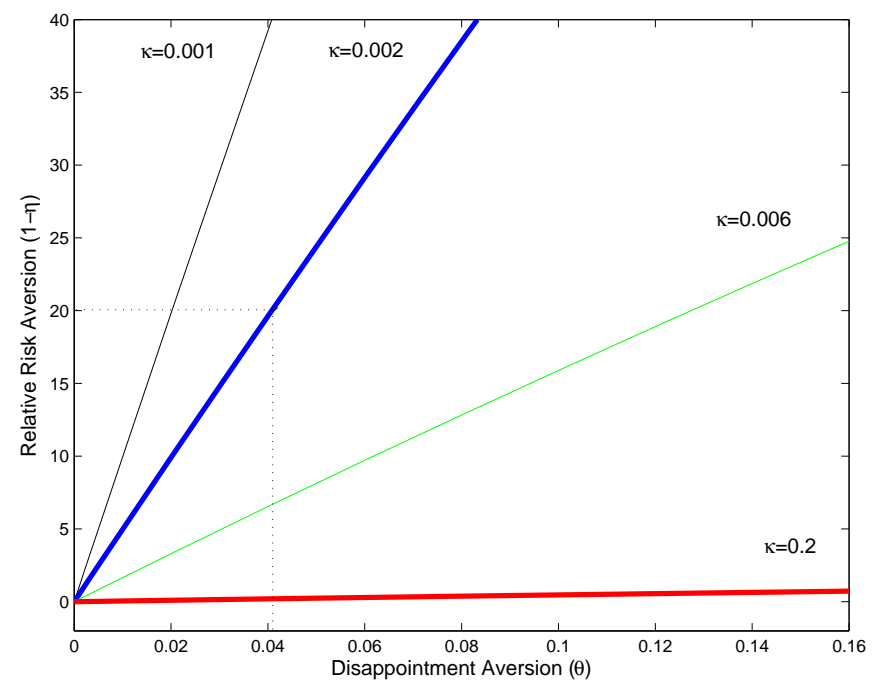

Figure 4: Comparison between risk-preferences.

The novelty, here, is not the insight that the universality requirement is not a challenge for first-order risk aversion preferences as much as it is for relations exhibiting

\footnotetext{
${ }^{18}$ Notice that the outcome of this simple exercise depends on the type of bet faced by the agent. The calibration results reported earlier in the paper show that, in the context of our model, a DA agents needs $\theta \approx 0.14$ - rather than $\theta \approx 0.04$ - in order to generate a relative risk aversion close to that of an EZ agent with $\eta=-17.53$. This caveat, however, does not affect the spirit of the exercise. Figure 4 shows that, in the case of the simple bets considered here, it takes $\kappa=0.006$ for an EZ agent with $\eta=-17.53$ and a DA agent with $\theta=.14$ to display the same relative risk aversion. Given the slope of the locus for $\kappa=0.2$, this does not change our conclusion in any appreciable way.
} 
second-order risk aversion. In the Introduction, we have mentioned that Epstein and Zin (1990a, 2001) and Bonomo and Garcia (1994) have exploited it in the case of an endowment economy. The novel results are that (i) a general equilibrium, production economy with disappointment averse agents, parameterized to generate realistic values for volatility of consumption growth and first moments of risk-free rate and equity premium, produces a variety of macroeconomic and asset pricing implications that are very close to those of a more standard model with Epstein-Zin preferences; and (ii) the same disappointment averse agents, when facing risk two orders of magnitude greater than business cycle risk, have a very moderate relative risk aversion. This also means that the challenge that universality constitutes for preferences with second-order risk aversion is not a valid reason for discarding Epstein-Zin preferences in general equilibrium asset pricing models.

\subsection{Generalized Disappointment Aversion}

We now discuss the generalization of Gul's notion of disappointment aversion due to Routledge and Zin (2004). Their work allows the disappointment threshold to differ from the certainty equivalent. ${ }^{19}$ This implies a different utility representation: ${ }^{20}$

$$
u(\mu)=\sum_{i=1}^{N} \pi_{i} u\left(x_{i}\right)-\theta \sum_{x_{i} \leq \xi \mu} \pi_{i}\left[u(\xi \mu)-u\left(x_{i}\right)\right]
$$

and a different stochastic discount factor:

$$
m\left(\varepsilon_{i} \mid k, z\right)=\beta e^{\lambda(\gamma-1)} \frac{1+\theta I\left(k^{\prime}, \varepsilon_{i}, \mu\right)}{1+\theta \xi^{\eta} \sum_{i} \pi\left(\varepsilon_{i} \mid \varepsilon\right) I\left(k^{\prime}, \varepsilon_{i}, \mu\right)}\left[\frac{c\left(k^{\prime}, \varepsilon_{i}\right)}{c(k, \varepsilon)}\right]^{\gamma-1}\left[\frac{v\left(k^{\prime}, \varepsilon_{i}\right)}{\mu\left(k^{\prime}, \varepsilon\right)}\right]^{\eta-\gamma},
$$

where $I\left(k^{\prime}, \varepsilon_{i}, \mu\right)=1$ if $v\left(k^{\prime}, \varepsilon_{i}\right) \leq \xi \mu$, and $I\left(k^{\prime}, \varepsilon_{i}, \mu\right)=0$ otherwise.

Table 9 shows that by setting $\theta=1.8, \xi=1.0069$, and leaving all other parameters at the same values as above, this specification implies similar values for the unconditional moments of asset returns.

The important question, however, is whether this parameterization generates a counter-cyclical market price of risk, similarly to what shown in Routledge and Zin (2004) in the case of a Mehra-Prescott economy. The answer is positive. Table 10 reports the average values of the market price of risk, conditional on all levels of the productivity shock, in the cases of DA and GDA preferences, respectively. The shocks are listed in increasing order of magnitude.

\footnotetext{
${ }^{19}$ Routledge and Zin (2004)'s main theoretical innovation is to allow for a more general definition of disappointment comparability.

${ }^{20}$ In the case of $\xi>1$, one needs to multiply the right-hand side by the constant $\left[1-\theta\left(\xi^{\eta}-1\right)\right]^{-1}$ and impose $\theta\left(\xi^{\eta}-1\right)<1$ in order to maintain $\mu(x)=x$ and monotonicity. See Section 2.3 of
} 


\begin{tabular}{ccccccc}
\hline & $\sigma_{C} / \sigma_{Y}$ & $\sigma_{I} / \sigma_{Y}$ & $E\left(r^{f}\right)$ & $S t d\left(r^{f}\right)$ & $E\left(r^{e}-r^{f}\right)$ & $S t d\left(r^{e}\right)$ \\
\hline \hline Model & 0.532 & 2.395 & $0.241 \%$ & $2.662 \%$ & $1.855 \%$ & $12.431 \%$ \\
\hline Data & 0.499 & 2.647 & $0.252 \%$ & $0.834 \%$ & $1.893 \%$ & $7.694 \%$ \\
\hline
\end{tabular}

Table 9: Unconditional Moments - Generalized Disappointment Aversion

\begin{tabular}{ccc}
\hline Shock & DA & GDA \\
\hline 1 & 0.095 & 0.247 \\
2 & 0.121 & 0.219 \\
3 & 0.153 & 0.176 \\
4 & 0.239 & 0.198 \\
5 & 0.121 & 0.090 \\
6 & 0.086 & 0.047 \\
\hline
\end{tabular}

Table 10: Conditional Market Price of Risk

Furthermore, the average expected equity premium, market price of risk, and Sharpe Ratio are higher in recessionary states than in the expansionary ones. ${ }^{21}$ This is in contrast with the models with EZ and DA preferences. In those cases, all of the three conditional moments are slightly higher in expansionary periods.

Unfortunately, the extent of the predictability of the equity premium generated by our model is not even close to that implied by the data. The results of regressing future cumulative equity premia on current price-dividend ratios, which we report in Table 11, make it clear. With respect to the EZ case, the magnitudes of the slope parameters are greater in absolute value, and the regressions' $R^{2}$ are slightly larger. However, the results are still very far from what implied by the data. Once again, the main issue appears to be the large and counterfactual volatility of the risk-free rate.

\section{Conclusion}

In this paper we have shown that when households have Epstein-Zin preferences, a general equilibrium production economy with convex investment adjustment costs is able to produce sensible asset pricing implications while generating plausible highand low-frequency macroeconomic dynamics. In particular, the model is able to match the unconditional first moments of risk-free rate and equity premium and to generate pro-cyclical price-dividend ratio and predictability of stock returns. Consistently with the empirical evidence, the predictability improves with the time horizon,

Routledge and Zin (2004).

${ }^{21}$ We define a recessionary state as one in which per capita output is below linear trend. Conversely, for expansionary states. 
Table 11: Predictability of the equity premium: DA Vs. GDA.

\begin{tabular}{ccccccc}
\hline \hline & \multicolumn{2}{c}{$E U$} & \multicolumn{2}{c}{ Data } & \multicolumn{2}{c}{$G D A$} \\
\hline Horizon (s) & Slope & $R^{2}$ & Slope & $R^{2}$ & Slope & $R^{2}$ \\
1 & -.00777 & .00 & -.117 & 0.08 & -0.018 & .004 \\
& $(-7.20)$ & & $(-2.27)$ & & $(-13.30)$ & \\
2 & -0.0142 & .00 & -.219 & 0.15 & -0.033 & .006 \\
& -9.36 & & $(-3.13)$ & & $(-17.23)$ & \\
3 & -.0191 & .00 & -.28 & 0.19 & -0.045 & .007 \\
& $(-10.26)$ & & $(-3.60)$ & & $(-19.27)$ & \\
5 & -.0259 & .00 & -.484 & 0.31 & -0.063 & .009 \\
& $(-10.79)$ & & $(-4.78)$ & & $(-21.10)$ & \\
7 & -.0287 & .00 & -.712 & 0.36 & -0.073 & .009 \\
& $(-10.2)$ & & $(-5.29)$ & & $(-21.11)$ & \\
\hline
\end{tabular}

Note: $t$ statistics in parenthesis.

and it is not matched by the predictability of dividend growth.

The levels of risk aversion implied by the model along the equilibrium path appears to be plausible. What appears not to be plausible is the attitude towards risk that the same preferences imply for bets with greater risk. Assuming disappointment aversion successfully addresses this issue. This is the case because i) for every relative risk aversion coefficient, there exists a value for the disappointment aversion parameter, such that the DA model has essentially the same implications for both quantities and prices as the model with Epstein-Zin preferences with that RRA coefficient and ii) the disappointment averse agent is faced with an atemporal lottery that has a coefficient of variation 100 times as large as that implied by our model, she displays the same relative risk aversion as an expected utility agent with logarithmic utility.

No matter the preference specification, the main shortcomings of the model appear to be (i) the excessive volatility of the risk-free rate and (ii) the lack of predictability of the equity premium. For the expected equity premium to be time-varying, the volatility of stock returns or the price of risk, or both must be time-varying. Since the stochastic process for the only shock in the model is homoscedastic and risk aversion is acylical, the occurrence of the latter problem is not surprising. Gul (1991)'s disappointment aversion as generalized in Routledge and Zin (2004), by generating a time-varying price of risk, has the potential of addressing the second of the two shortcomings. This result mirrors that obtained by Routledge and Zin (2004) in the case of a Mehra-Prescott economy. However, the counterfactually high volatility of the risk free rate undermines the model's ability to generate predictability to the extent implied by the data. 
We believe that understanding how to amend the model in order to reduce the volatility of the risk-free rate should be at the top of the research agenda. In the present framework, the excess volatility is the result of the perfect rigidity of bond supply, the high rigidity of bond demand, implied by the low intertemporal elasticity of substitution, the fast-rising investment adjustment costs, and the relatively low persistence of productivity shocks. A drastic change in the parameters governing the elasticity of substitution and the adjustment costs would impair the model's ability to generate a sizeable equity premium. On the one hand, increasing the persistence of the productivity shock would make our framework consistent with most consumptionbased asset pricing studies, that assume i.i.d. consumption growth. On the other hand, doing so would represent somewhat of an infringement of the methodological approach that calls for the use of direct evidence for the parameterization, whenever possible. Allowing for a bond supply schedule with non-zero elasticity seems to us the most promising direction. This could be accomplished by assuming some form of heterogeneity across households, or by introducing a government entity that finances a deficit by issuing securities to the public. 


\section{A Data}

Our business cycle data is drawn from FRED (Federal Reserve Economic Data) at http://research.stlouisfed.org/fred2/. Output is variable GDPC96 (Real Gross Domestic Output). Consumption is the sum of variables PCNDGC96 and PCESVC96 (Real Personal Consumption Expenditures on Nondurable Goods, and on Services, respectively). Investment is variable FPIC96 (Real Fixed Private Investment). All series are quarterly from 1947:1 to 2005:4, expressed in billions of chained 2000 dollars, and seasonally adjusted. Employment is variable AWHI (Total Weekly Hours in All Private Industries), which is monthly - we averaged to obtain quarterly observations.

Our data on asset returns is drawn from CRSP (Center for Research in Security Prices at the University of Chicago Business School). Nominal Equity Returns correspond to the NYSE variable VWRETD (Value-Weighted Return on the NYSE Index, including Dividends). The nominal risk-free returns correspond to the yields to maturity on 90-day T-Bills (based upon the average between bid and ask prices, and drawn from the Fama T-Bill Term Structure Supplemental Files). All series are quarterly from 1947:1 to 2005:4. (Gross) real returns were computed as gross nominal returns divided by the gross inflation rate. The inflation rate is based upon the CPI from FRED, variable CPIAUCNS (CPI for all urban consumers, all items). This variable is not seasonally adjusted, and it is monthly - quarterly observations correspond to the value of the index in the last month of each quarter.

We computed price-dividend ratios as follows. The variable VWRETD provides $\left(P_{t}+D_{t}\right) / P_{t-1}-1$, where $P_{t}$ is the value-weighted index and $D_{t}$ are dividends at time $t$. From the CRSP dataset we also obtained NYSE variable VWINDX, which provides $P_{t}$ (the value of the index relative to a base year). Price-Dividend ratios are thus the inverse of $\left(1+\mathrm{VWRETD}_{t}\right) \times \mathrm{VWINDX}_{t-1} / \mathrm{VWINDX}_{t}-1$.

We ran the return predictability regressions on an annual basis. We computed annual dividends by summing up quarterly dividends. Annual price-dividend ratios are the NYSE value-weighted index for the last quarter divided by annual dividends. The real returns between years $t$ and $t+k$ were computed by summing up all real quarterly returns between the two dates.

Table 12 compares our estimates for the first two moments of risk-free rate and equity premium with those reported by other papers in the literature on asset pricing in general equilibrium production economies. 


\begin{tabular}{lccccc}
\hline & $E\left(r^{f}\right)$ & $S t d\left(r^{f}\right)$ & $E\left(r^{e}-r^{f}\right)$ & $S t d\left(r^{e}-r^{f}\right)$ & $S t d\left(r^{e}\right)$ \\
\hline This paper & 1.01 & 1.67 & 7.57 & 15.16 & 15.39 \\
Tallarini (2000) & 0.92 & 1.60 & 1.97 & 15.64 & - \\
Jermann (1998) & 0.80 & 5.67 & 6.18 & - & 16.54 \\
Boldrin, Christiano, and Fisher (2001) & 1.19 & 5.27 & 6.63 & - & 19.4 \\
Danthine and Donaldson (2002) & 0.8 & 5.67 & 6.18 & 16.67 & 16.54 \\
Guvenen (2005) - long & 1.91 & 5.44 & 6.17 & 19.4 & - \\
Guvenen (2005) - short & 1.33 & 2.70 & 7.21 & 17.0 & - \\
\hline
\end{tabular}

Table 12: Moments estimates (Returns are yearly)

\section{B Decentralization}

Here we describe our decentralization of the planner's problem illustrated in the main body of the paper. For the sake of clarity, we will consider the case in which agents maximize expected discounted utility $(\theta=0$ and $\gamma=\eta)$. The generalization to the cases of $\gamma \neq \eta$ and $\theta>0$ is straightforward and is omitted for the sake of brevity.

Our decentralization is essentially the same as in Cochrane (1991), Jermann (1998), and Boldrin, Christiano, and Fisher (2001). Because of our assumptions, there is no loss of generality in assuming that production is carried out by one representative firm, owned by the households. The firm maximizes the expected discounted sum of dividends, does not issue new shares, and finances investment exclusively through retained earnings.

At every $t$, and for given capital $K_{t}$, the firm's value $P_{t}$ is

$$
\begin{aligned}
P_{t} \equiv \max _{\left\{K_{t+v}\right\}_{v=1}^{\infty}} E_{t} \sum_{v=0}^{\infty} \frac{\lambda_{t+v}}{\lambda_{t}} D_{t+v} \\
\text { s.t. } D_{t+v}=K_{t+v}^{\alpha}\left(z_{t+v} L_{t+v}\right)^{1-\alpha}-w_{t+v} L_{t+v}-I_{t+v} \\
\quad I_{t+v}=K_{t+v+1}-(1-\delta) K_{t+v}+g\left(K_{t+v}, K_{t+v+1}\right),
\end{aligned}
$$

where $g\left(K_{t+v}, K_{t+v+1}\right) \equiv\left|\frac{K_{t+v+1}}{K_{t+v}}-\psi\right|^{\iota}$ and $\lambda_{t+v} / \lambda_{t}$ is the owners' marginal rate of substitution between consumption at the dates $t$ and $t+v$. Denote $g_{i}(\cdot, \cdot)$ as the partial derivatives with respect to argument $i$. Necessary condition for the optimum is that, at every $t$ :

$$
E_{t}\left[\frac{\lambda_{t+1}}{\lambda_{t}} \frac{\alpha K_{t+1}^{\alpha-1}\left(z_{t+1} L_{t+1}\right)^{1-\alpha}+(1-\delta)-g_{1}\left(K_{t+1}, K_{t+2}\right)}{1+g_{2}\left(K_{t}, K_{t+1}\right)}\right]=1
$$


Multiplying numerator and denominator by $K_{t+1}$, one obtains

$$
E_{t}\left[\frac{\lambda_{t+1}}{\lambda_{t}} \frac{\alpha Y_{t+1}+(1-\delta) K_{t+1}-g_{1}\left(K_{t+1}, K_{t+2}\right) K_{t+1}}{\left[1+g_{2}\left(K_{t}, K_{t+1}\right)\right] K_{t+1}}\right]=1 .
$$

Now notice that

$$
g_{1}\left(K_{t+1}, K_{t+2}\right) K_{t+1}=g\left(K_{t+1}, K_{t+2}\right)-g_{2}\left(K_{t+1}, K_{t+2}\right) K_{t+2}
$$

and that

$$
\alpha Y_{t+1}+(1-\delta) K_{t+1}=D_{t+1}+K_{t+2}+g\left(K_{t+1}, K_{t+2}\right) .
$$

The two imply

$$
E_{t}\left[\frac{\lambda_{t+1}}{\lambda_{t}} \frac{D_{t+1}+\left[1+g_{2}\left(K_{t+1}, K_{t+2}\right)\right] K_{t+2}}{\left[1+g_{2}\left(K_{t}, K_{t+1}\right)\right] K_{t+1}}\right]=1
$$

For given shareholding $a_{t}$, the household's optimization problem at time $t$ writes as

$$
\begin{aligned}
& \max _{\left\{a_{t+v}\right\}_{v=1}^{\infty}} E_{t} \sum_{v=0}^{\infty} \beta^{\varphi v} c_{t+v}^{\gamma}, \\
& \text { s.t. } w_{t+v} l_{t+v}+a_{t+v}\left(P_{t+v}+D_{t+v}\right)=c_{t+v}+a_{t+v+1} P_{t+v}
\end{aligned}
$$

where $c_{t+v}$ is per-capita consumption and $l_{t+v}$ is the inelastic supply of labor. Necessary condition for the optimum is that, at every $t$ :

$$
E_{t}\left[\frac{\lambda_{t+1}}{\lambda_{t}} \frac{P_{t+1}+D_{t+1}}{P_{t}}\right]=1
$$

where

$$
\lambda_{t+v} \equiv\left[\beta e^{\varphi}\right]^{v} \gamma c_{t+v}^{\gamma-1}
$$

Finally, (3) and (4) imply that the conditional gross return to the firm's owners from time $t$ to time $t+1$ is

$$
R_{t, t+1}^{e} \equiv \frac{D_{t+1}+P_{t+1}}{P_{t}}=\frac{D_{t+1}+\left[1+g_{2}\left(K_{t+1}, K_{t+2}\right)\right] K_{t+2}}{\left[1+g_{2}\left(K_{t}, K_{t+1}\right)\right] K_{t+1}}
$$

Notice that the latter expression equal the right-hand side of equation (2) in Section 2 .

\section{References}

Abel, A. (2002): "On the Invariance of the Rate of Return to Convex Adjustment Costs," Review of Economic Dynamics, 5, 586-601. 
Abel, A., And J. Eberly (2002): "Investment and q with Fixed Costs: An Empirical Analysis," Working Paper, Wharton School and Kellogg School.

Aruoba, B., J. Fernandez-Villaverde, and J. Rubio-Ramirez (2006): "Comparing Solution Methods for Dynamic Equilibrium Economies," Journal of Economic Dynamics and Control, 30, 2477-2508.

Backus, D., B. Routledge, and S. Zin (2004): "Exotic Preferences for Macroeconomists," in NBER Macroeconomics Annual, ed. by M. Gertler, and K. Rogoff, pp. 319-390. MIT Press.

Bansal, R., And A. Yaron (2004): "Risks for the Long Run: A Potential Resolution of Asset Pricing Puzzles," Journal of Finance, 59, 1481-1509.

Barnett, S., And P. Sakellaris (1998): "Nonlinear Response of Firm Investment to Q: Testing a Model of Convex and Non-convex Adjustment Costs," Journal of Monetary Economics, 42, 261-288.

Boldrin, M., L. Christiano, and J. Fisher (2001): "Habit Persistence, Asset Returns, and the Business Cycle," American Economic Review, 91, 149-166.

Bonomo, M., and R. Garcia (1994): "Disappointment Aversion as a Solution to the Equity Premium and the Risk-Free Rate Puzzles," Working Paper 94s-14, Cirano.

Campbell, J. (1999): "Asset Prices, Consumption, and the Business Cycle," in Handbook of Macroeconomics, ed. by J. Taylor, and M. Woodford, pp. Volume 1, Chapter 19. North Holland, Amsterdam.

Campbell, J., and J. Cochrane (1999): "By Force of Habit: A ConsumptionBased Explanation of Aggregate Stock Market Behavior," Journal of Political Economy, 107, 205-251.

Campbell, J., and R. Shiller (1988): "The Dividend-Price Ratio and Expectations of Future Dividends and Discount Factors," Review of Financial Studies, 1, $195-227$.

Chew, S. H. (1989): "Aximatic Utility Theories with the Betweenness Property," Annals of Operations Research, 19, 273-298. 
Cochrane, J. H. (1991): "Production-Based Asset Pricing and the Link Between Stock Returns and Economic Fluctuations," Journal of Finance, 46(1), 209-37.

(1997): "Where is the Market going? Uncertain Facts and Novel Theories," Economic Perspectives, 21(6), 3-37.

(2006): "Financial Markets and the Real Economy," Graduate School of Business, University of Chicago.

Cooley, T., And E. Prescott (1995): "Economic Growth and Business Cycles," in Modern Business Cycle Theory, ed. by T. Cooley, and E. Prescott, pp. 1-38. Princeton University Press.

Croce, M. (2006): "Welfare Costs and Long Run Consumption Risk in Production Economy," Working Paper, New York University.

Danthine, J.-P., and J. Donaldson (2002): "Labour Relations and Asset Returns," Review of Economic Studies, 69, 41-64.

Dekel, E. (1986): "An Axiomatic Characterization of Preferences Under Uncertainty: Weakening the Independence Axiom," Journal of Economic Theory, 40, 304-318.

Dohmen, T., A. Falk, D. Huffman, U. Sunde, J. Schupp, and G. Wagner (2005): "Individual Risk Attitudes: New Evidence from a Large, Representative, Experimentally-Validated Survey," IZA Discussion Paper \# 1730.

EberLy, J. (1997): "International Evidence on Investment and Fundamentals," European Economic Review, 41, 1055-1078.

Epstein, L., And S. Zin (1989): "Substitution, Risk Aversion, and the Temporal Behavior of Consumption and Asset Returns: A Theoretical Framework," Econometrica, 57, 937-969.

- (1990a): "First-order Risk Aversion and the Equity Premium Puzzle," Journal of Monetary Economics, 26, 387-407.

- (1990b): "Substitution, Risk Aversion, and the Temporal Behavior of Consumption-Based Asset Returns: An Empirical Analysis," Journal of Political Economy, 99, 263-286. 
- (2001): "The Independence Axiom and Asset Returns," Journal of Empirical Finance, 8, 537-572.

FAma, E., AND K. French (1988a): "Dividend Yields and Expected Stock Returns," Journal of Financial Economics, 22, 3-27.

— (1988b): "Permanent and Temporary Components of Stock Prices," Journal of Political Economy, 96, 246-273.

Friend, I., And M. Blume (1975): "The Demand for Risky Assets," American Economic Review, 65, 900-922.

Gollier, C. (2001): The Economics of Risk and Time. MIT Press, Cambridge, MA.

Gomme, P., B. Ravikumar, and P. Rupert (2006): "The Return to Capital and the Business Cycle," University of Iowa.

Gul, F. (1991): "A Theory of Disappointment Aversion," Econometrica, 59, 667686.

Guvenen, F. (2005): "A Parsimonious Macroeconomic Model for Asset Pricing: Habit Formation or Cross-sectional Heterogeneity?," Working Paper, University of Texas at Austin.

Hall, R. (1988): "Intertemporal Substitution in Consumption," Journal of Political Economy, 96, 339-357.

Hansen, L. P., T. J. Sargent, and T. D. Tallarini (1999): "Robust Permanent Income and Pricing," Review of Economic Studies, 66, 873-97.

Hansen, L. P., and K. Singleton (1982): "Generalized Instrumental Variables Estimation of Nonlinear Rational Expectations Models," Econometrica, 50, 126986.

Jermann, U. (1998): "Asset Pricing in Production Economies," Journal of Monetary Economics, 41, 257-275.

Kandel, S., and R. Stambaugh (1991): "Asset Returns and Intertemporal Preferences," Journal of Monetary Economics, 27, 39-71.

Kocherlakota, N. R. (1990a): "On Tests of Representative Consumer Asset Pricing Models," Journal of Monetary Economics, 26, 285-304. 
- (1990b): "On the 'Discount' Factor in Growth Economies," Journal of Monetary Economics, 25, 43-47.

_ (1996): "The Equity Premium: It's Still a Puzzle," Journal of Economic Literature, 34, 42-71.

Koopmans, T. (1960): "Stationary Ordinal Utility and Impatience," Econometrica, 28, 287-309.

Kreps, D., And E. Porteus (1978): "Temporal Resolution of Uncertainty and Dynamic Choice Theory," Econometrica, 46, 185-200.

Kydland, F., and E. Prescott (1982): "Time to Build and Aggregate Fluctuations," Econometrica, 50, 1345-1370.

— (1990): "Business Cycles: Real Facts and a Monetary Myth," Federal Reserve Bank of Minneapolis Quarterly Review, 14, 3-18.

LuCAs, R. E. J. (1978): "Asset Prices in an Exchange Economy," Econometrica, 46, 1429-1445.

Mehra, R., And E. Prescott (1985): "The Equity Premium - A Puzzle," Journal of Monetary Economics, 15, 145-161.

Papanikolaou, D. (2006): "Investment-Specific Technological Change and Asset Prices," Working Paper, MIT.

Pesendorfer, W. (2006): "Behavioral Economics Comes of Age: A Review Essay on Advances in Behavioral Economics," Journal of Economic Literature, 44, 712721.

Rabin, M. (2000): "Risk Aversion and Expected Utility Theory: A Calibration Theorem," Econometrica, 68, 1281-1292.

Routledge, B., And S. ZIN (2004): "Generalized Disappointment Aversion and Asset Prices," Journal of Finance, Forthcoming.

Rouwenhorst, K. G. (1995): "Asset Pricing Implications of Equilibrium Business Cycle Models," in Modern Business Cycle Theory, ed. by T. Cooley, and E. Prescott, pp. 1294-330. Princeton University Press. 
Segal, U., And A. Spigal (1990): "First-order Versus Second-order Risk Aversion," Journal of Economic Theory, 51, 111-125.

Tallarini, T. (2000): "Risk-sensitive Real Business Cycles," Journal of Monetary Economics, 45, 507-532.

von Furtstenburg, G. (1977): "Corporate Investment: Does Market Valuation Matter in the Aggregate?," Brookings Papers on Economic Activity, 2, 347-397.

Weil, P. (1989): "The Equity Premium Puzzle and the Risk-Free Rate Puzzle," Journal of Monetary Economics, 24, 401-421. 